\title{
Treatment patterns and clinical outcomes in patients with advanced non-small cell lung cancer initiating first-line treatment in the US community oncology setting: a real-world retrospective observational study
}

\author{
Eric Nadler ${ }^{1,2} \cdot$ Bhakti Arondekar $^{3} \cdot$ Kathleen Marie Aguilar $^{2}$ (1) $\cdot$ Jie Zhou $^{2} \cdot$ Jane Chang $^{3} \cdot$ Xinke Zhang $^{4,5}$. \\ Vivek Pawar ${ }^{4,5}$
}

Received: 29 May 2020 / Accepted: 18 August 2020 / Published online: 2 December 2020

(C) The Author(s) 2020

\begin{abstract}
Purpose Treatments for advanced non-small cell lung cancer (NSCLC) have evolved to include targeted and immuno-oncology therapies, which have demonstrated clinical benefits in clinical trials. However, few real-world studies have evaluated these treatments in the first-line setting.

Methods Adult patients with advanced NSCLC who initiated first-line treatment with chemotherapy, targeted therapies (TT), or immuno-oncology-based regimens in the US Oncology Network (USON) between March 1, 2015, and August 1, 2018, were included and followed up through February 1, 2019. Data were sourced from structured fields of USON electronic health records. Patient and treatment characteristics were assessed descriptively, with Kaplan-Meier methods used to evaluate time-to-event outcomes, including time to treatment discontinuation (TTD) and overall survival (OS). Adjusted Cox regression analyses and inverse probability of treatment weighting (IPTW) were performed to control for covariates that may have affected treatment selection and outcomes.

Results Of 7746 patients, $75.6 \%$ received first-line systemic chemotherapy, $11.7 \%$ received immuno-oncology monotherapies, $8.5 \%$ received TT, and $4.2 \%$ received immuno-oncology combination regimens. Patients who received immuno-oncology monotherapies had the longest median TTD (3.5 months; 95\% confidence interval [CI], 2.8-4.2) and OS (19.9 months; 95\% CI, 16.6-24.1). On the basis of multivariable Cox regression and IPTW, immuno-oncology monotherapy was associated with reduced risk of death and treatment discontinuation relative to other treatments.

Conclusion These results suggest that real-world outcomes in this community oncology setting improved with the introduction of immuno-oncology therapies. However, clinical benefits are limited in certain subgroups and tend to be reduced compared with clinical trial observations.
\end{abstract}

Keywords Electronic health record · Immuno-oncology $\cdot$ Overall survival $\cdot$ Time to treatment discontinuation $\cdot$ Community oncology

\section{Introduction}

Electronic supplementary material The online version of this article (https://doi.org/10.1007/s00432-020-03414-4) contains supplementary material, which is available to authorized users.

Kathleen Marie Aguilar

kat.aguilar@mckesson.com

1 Texas Oncology-Baylor Charles A. Sammons Cancer Center, Dallas, TX, USA

2 McKesson Life Sciences, 10100101 Woodloch Forest Dr, The Woodlands, TX, USA
The treatment landscape for advanced, unresectable, and/or metastatic non-small cell lung cancer (NSCLC) is evolving. Although doublet and triplet systemic chemotherapies were

3 Pfizer Inc, New York, NY, USA

4 EMD Serono Research \& Development Institute, Inc., Billerica, MA, USA; an affiliate of Merck KGaA, Darmstadt, Germany, Billerica, MA, USA

5 Merck KGaA, Darmstadt, Germany 
the mainstay treatment of advanced NSCLC for decades, limited improvements in survival rates and high occurrence of toxicity have been noted (Azim et al. 2009, 2016; Bittoni et al. 2018; Kaniski et al. 2017; Xia et al. 2017). An analysis of the Surveillance, Epidemiology, and End Results Program (SEER) database indicated that 5-year survival rates for patients diagnosed with metastatic NSCLC increased from $2.0 \%$ (95\% confidence interval [CI], 1.80-2.20\%) to only $4.2 \%$ (95\% CI, 4.10-4.40\%) between 1988 and 2008 (Xia et al. 2017). Another evaluation of the SEER database showed that the median overall survival (OS) in patients with stage IIIB/IV NSCLC was 4 months in 1996 and 5 months in 2005 and 2010 (Kaniski et al. 2017). A systematic review of 8 clinical trials published between 2000 and 2008 revealed that median OS associated with doublet or triplet therapy for advanced NSCLC was 37 and 42 weeks, respectively (Azim et al. 2016). Additionally, both regimens are associated with a high occurrence of adverse events (Azim et al. 2009, 2016; Bittoni et al. 2018).

Greater insight into the molecular mechanisms of NSCLC has resulted in the identification of prognostic biomarkers and the development of targeted therapies associated with improved clinical outcomes and safety profiles compared with systemic chemotherapy (NCCN Guidelines for NonSmall Cell Lung Cancer 6.2020). Several targeted therapies have demonstrated clinical benefits for patients with specific biomarkers, and current National Comprehensive Cancer Network (NCCN) guidelines (version 6.2020) recommend these regimens as first-line (1L) treatment for patients with sensitizing epidermal growth factor receptor $(E G F R)$, anaplastic lymphoma kinase $(A L K)$, ROS proto-oncogene 1 receptor tyrosine kinase (ROS1), proto-oncogene B-Raf $(B R A F) \mathrm{V600 \textrm {E }}$, neurotrophic tyrosine kinase (NTRK) gene fusion, or programmed death-ligand 1 (PD-L1) biomarkers.

Until recently, treatment options for patients without these biomarkers were limited to traditional systemic chemotherapies. On the basis of specific biomarkers, NCCN guidelines (version 6.2020) provide specific treatment recommendations for targeted therapies. For example, recommended $1 \mathrm{~L}$ therapies for patients with sensitizing EGFR mutations include osimertinib (preferred, category 1), erlotinib (alone or with ramucirumab or bevacizumab), afatinib, gefitinib, and dacomitinib.(NCCN Guidelines for Non-Small Cell Lung Cancer 6.2020) In addition to conventional targeted therapies, immuno-oncology (IO) agents are now recommended for patients with PD-L1 expression and favorable performance status (PS). For patients with PD-L1-positive NSCLC ( $\geq 50 \%$ expression) without other prognostic biomarkers, pembrolizumab and atezolizumab monotherapies, along with platinum-based IO combination therapy, are preferred $1 \mathrm{~L}$ treatments in the current NCCN guidelines (version 6.2020). IO combination therapies that include pembrolizumab, atezolizumab, or nivolumab are also recommended for patients with PD-L1 expressions of less than 50\% who lack other prognostic biomarkers.

IO agents, either alone or in combination with other therapies, have demonstrated promising results in clinical trials, even in patients who lack the PD-L1 mutation (Table 1). KEYNOTE-024 and -042 showed superior efficacy of pembrolizumab monotherapy compared with chemotherapy, and KEYNOTE-189 and -407 showed superior efficacy of pembrolizumab and chemotherapy compared with placebo and chemotherapy (Gadgeel et al. 2020; Gandhi et al. 2018; Mok et al. 2019a, b; Paz-Ares et al. 2018; Reck et al. 2016, 2019a, b). IMpower131 and 132 showed superior efficacy of atezolizumab and carboplatin/paclitaxel over carboplatin/ paclitaxel alone, and IMpower150 showed superior efficacy of atezolizumab, bevacizumab, and carboplatin/paclitaxel over bevacizumab and carboplatin/paclitaxel alone (Jotte et al. 2018, 2019; Papadimitrakopoulou et al. 2018; Socinski et al. 2018a, b). CheckMate 227 demonstrated superior efficacy of nivolumab plus ipilimumab over platinum doublet chemotherapy (Hellmann et al. 2018, 2019).

On the basis of trial results, NCCN guidelines (version 6.2020) recommend IO regimens as $1 \mathrm{~L}$ treatment for patients with advanced NSCLC without other prognostic biomarkers, according to their histology results and PS. (NCCN Guidelines for Non-Small Cell Lung Cancer 6.2020). For patients with Eastern Cooperative Oncology Group (ECOG) PS of 0/1 and adenocarcinoma, large cells, or another histology not otherwise specified, pembrolizumab alone or in combination with pemetrexed and either carboplatin or cisplatin, as well as atezolizumab monotherapy, are preferred regimens. For patients with squamous cell carcinoma and an ECOG PS of 0/1, pembrolizumab alone or in combination with carboplatin and paclitaxel, as well as atezolizumab monotherapy, are preferred regimens.

Since the US Food and Drug Administration's approval of IO therapies for advanced NSCLC, the use of these treatments has increased in the US community oncology setting (Khozin et al. 2019b). However, few studies have examined the real-world treatment patterns and clinical outcomes of these therapies. These studies have mostly included patients with previously treated advanced NSCLC, lacked comparisons between treatments, and/or limited the patient population to those with PD-L1 expression (Khozin et al. 2018; Molife et al. 2019; Nadler et al. 2018; Schwartzberg et al. 2019; Velcheti et al. 2019; Weis et al. 2019). Further research on IO use in patients with advanced NSCLC treated in the community oncology setting is needed, as there may be differences in real-world clinical outcomes compared with clinical trial outcomes due to underlying variation in patient populations and methodology (Khozin et al. 2019a).

The aim of this study was to provide real-world insight into contemporary treatment patterns and outcomes in patients with advanced NSCLC who initiated $1 \mathrm{~L}$ treatment 


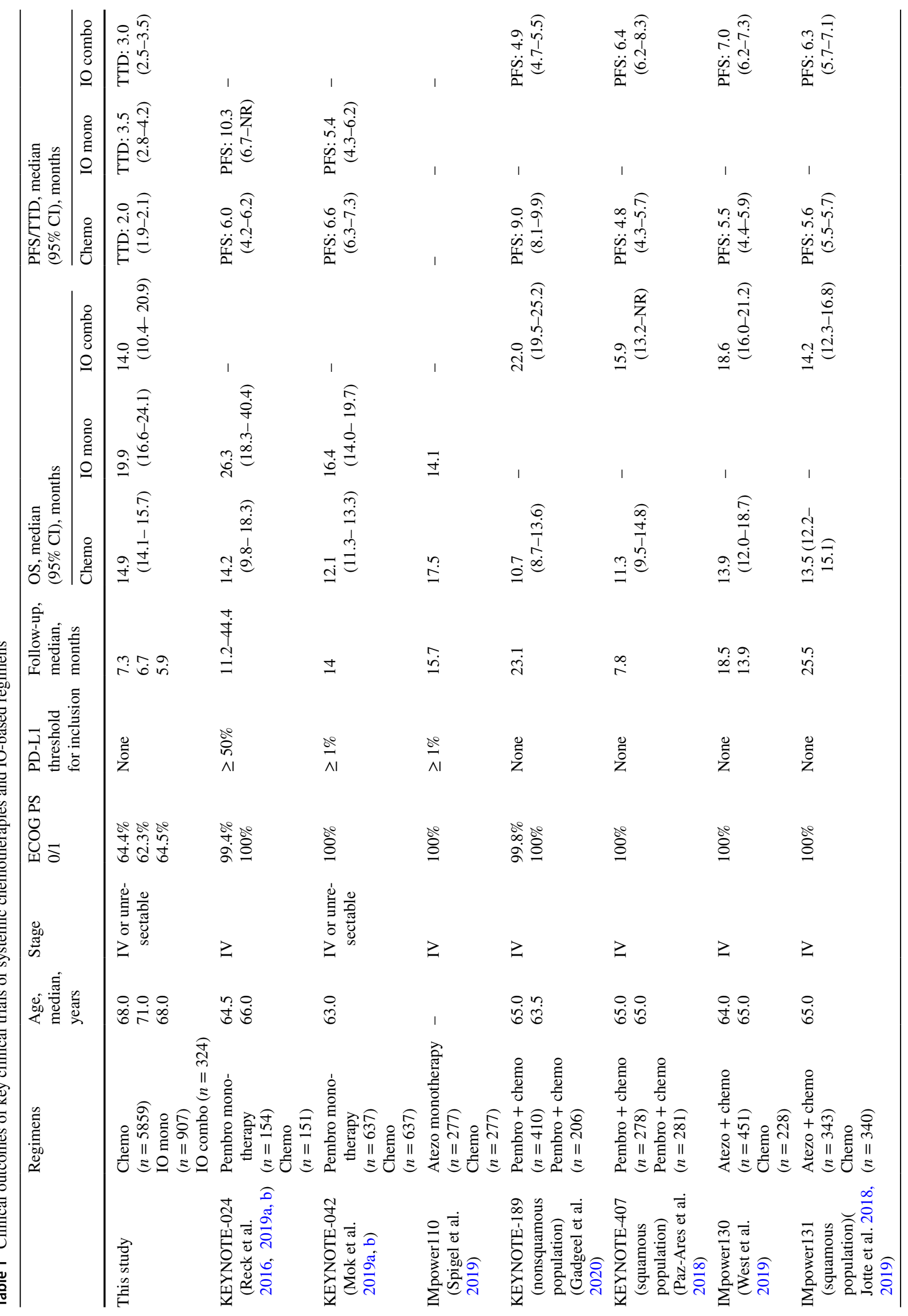


674

Journal of Cancer Research and Clinical Oncology (2021) 147:671-690

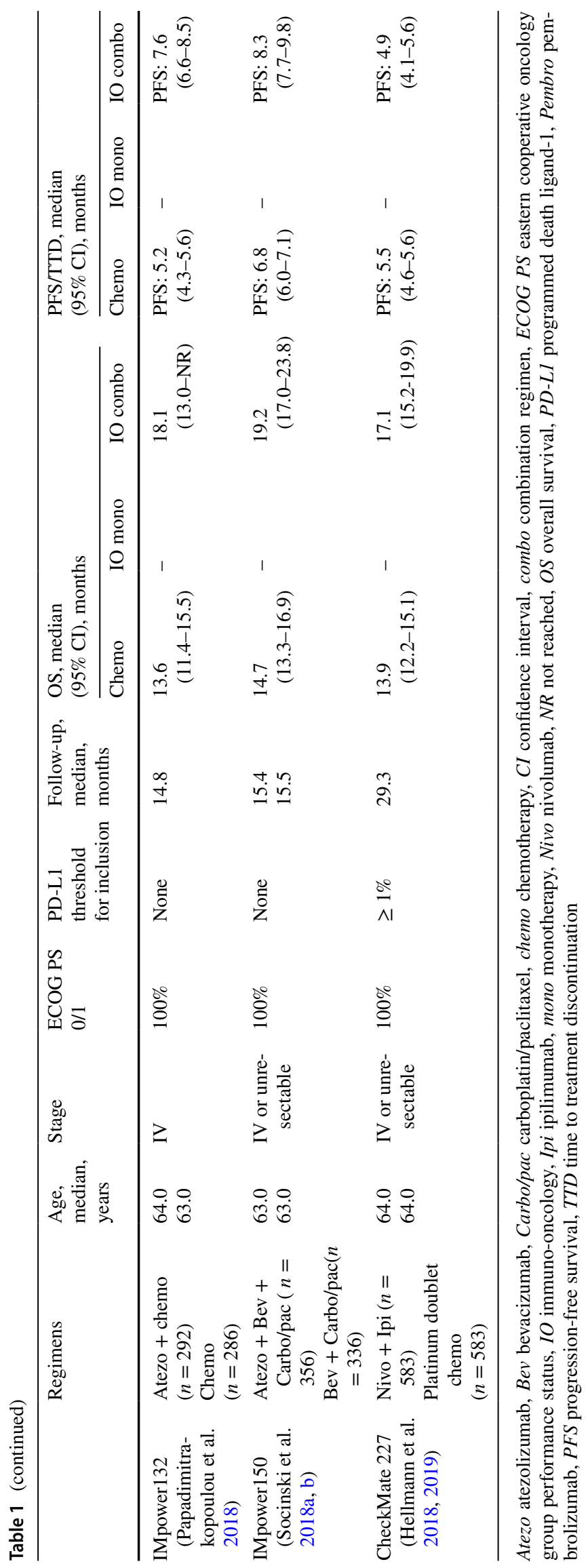

Springer 
within a large network of US community oncology practices. This insight will help providers and health benefits administrators navigate complex treatment pathways to determine appropriate regimens based on patient and disease characteristics. In addition to examining how IO therapies may have changed the treatment landscape, we compared clinical outcomes across treatment types.

\section{Patients and methods}

\section{Study design and data sources}

This was a retrospective, observational, descriptive study of adult patients with advanced NSCLC who initiated $1 \mathrm{~L}$ treatment with systemic chemotherapy, targeted therapies, or IO-based regimens between March 1, 2015, and August 1, 2018, within the US Oncology Network (USON). Initiation of $1 \mathrm{~L}$ treatment was considered the index event, and eligible patients were followed up through February 1, 2019. Patients younger than 18 years at diagnosis, those with fewer than 2 visits after index, clinical trial participants, and those with another documented primary cancer were excluded. Additionally, patients with documented EGFR mutations or $A L K$ rearrangements were excluded to focus on patients who would be eligible for 1L IO therapies, which are generally indicated for patients with an $E G F R$ - and $A L K$-negative status. Patients with other documented biomarkers, including ROS1, were included as $1 \mathrm{~L}$ IO therapies were not counterindicated for these patients at the time of the study.

The USON is a community-based network of 470 oncology clinics that treat over 1 million patients annually (The US Oncology Network 2018). Study data were primarily sourced from structured fields of the USON's electronic healthcare record (EHR), iKnowMed (iKM), with supplemental vital status provided by the Social Security Administration's Limited Death Access Master File. Patients who received care at USON clinics that did not use the full iKM capacities or who had data that were inaccessible for research purposes were excluded.

Patients with a diagnosis of NSCLC were identified through a review of iKM's discrete diagnosis and histology fields, which were populated during the routine course of care. Patients with advanced disease status were identified by having $\geq 1$ of the following indicators: (1) receipt of a numbered line of therapy; (2) stage IV disease; (3) indication of metastases based on tumor, node, metastases (TNM) stage; (4) location record of metastatic disease; or (5) current or prior disease status containing reference to advanced or metastatic disease.

The study was reviewed and granted an exception and waiver of consent by the US Oncology, Inc, Institutional
Review Board. This study was conducted in accordance with the Declaration of Helsinki.

\section{Statistical analysis}

Baseline characteristics at initiation of $1 \mathrm{~L}$ treatment (overall and by treatment group) and treatment patterns, including distribution of regimens over time and sequences, were assessed descriptively. The regimens were classified as chemotherapy (eg, carboplatin+paclitaxel, carboplatin+pemetrexed), targeted therapy (bevacizumab+ carboplatin+paclitaxel, bevacizumab+carboplatin+pemetre xed), IO monotherapy (eg, pembrolizumab, nivolumab), or IO combination therapy (pembrolizumab+carboplatin+pe metrexed; Supplementary Table 1). Combination regimens were identified as treatments with overlapping treatment durations that were started within 14 days of each other. Time-to-event outcomes were assessed using the KaplanMeier method, with log-rank testing used to assess differences between the four 1L treatment groups.

Because it was not possible to assess dates of disease progression with the available data, time to treatment discontinuation (TTD) and time from 1L treatment initiation to $2 \mathrm{~L}$ discontinuation or death were included; these measures were previously shown to be real-world proxies for progression-free survival (PFS) (Blumenthal et al. 2019; European Medicines Agency 2017). TTD was defined as the interval between $1 \mathrm{~L}$ treatment initiation and discontinuation for any reason (including death).

OS was defined as the interval between $1 \mathrm{~L}$ treatment initiation and the date of death (any cause). For time-to-event analyses, patients who did not experience the event during the study observation period were censored on the study end date or the last visit date available in the dataset, whichever occurred first.

As with any observational study, there was potential confounding when comparing treatment effects. Two methods were used to mitigate the bias. First, adjusted Cox regression analyses were performed to assess the relative effectiveness (ie, hazard ratio [HR]) of targeted therapy, IO monotherapy, and IO combination therapy vs chemotherapy, respectively, on OS and TTD, controlling for patient characteristics at baseline, including age, sex, body mass index (BMI), tobacco use, stage at diagnosis, ECOG PS, sites of metastasis, and histology. To construct these Cox models, baseline covariates and $1 \mathrm{~L}$ treatment category were included in univariate models, and a stepwise selection approach was used to identify covariates for the multivariable models, with $P$ $\leq .25$ for entry and $\leq .15$ for retention (Bursac et al. 2008).

Second, the inverse probability of treatment weighting (IPTW) method was applied to balance baseline demographic and clinical characteristics between the comparison cohorts (no limits were posed on these weights). To address 
the concern that patients treated under the different therapies have different characteristics, the propensity score method for multiple treatments was applied (McCaffrey et al. 2013). Specifically, generalized boosting models were used to generate propensity scores for each treatment group (available in the R package twang [Toolkit for Weighting and Analysis of Nonequivalent Groups]) (McCaffrey et al. 2013; RAND Corporation 2020).

Compared with a multinomial logistic model that is usually used to generate propensity scores for multiple treatment groups, the generalized boosted model is a nonparametric machine-learning classifying technique that has the advantage of automated variable selection and can provide more stable weights. In particular, multinomial logistic regression may require addition of many polynomial and cross product terms for covariates that are not balanced, and, in some cases, it may not be possible to test variation of possible polynomial and interaction terms. This approach also assumes appropriate candidate terms are tested in the model. Beyond the challenges of implementing this algorithm, linearity assumptions of logistic regression can lead to very small probabilities and extremely large weights (Harder et al. 2010; Kang and Schafer 2007; Lee et al. 2010).

The generalized boosted model was set up to achieve the best balance in covariates between each treatment group and the entire patient population. To obtain the optimum balance, the maximum number of regression trees was set to 10,000 . In every iteration, the model with the additional tree was assessed to see if the balance measure was improved. The final model with the number of trees providing the best balance of baseline characteristics was selected. To assess the balance of each characteristic, the absolute standardized mean difference of effect size (standardized bias) or Kolmogorov-Smirnov statistic was estimated in tabular and graphical forms (Supplementary Figure 1 and Supplementary Table 2).

After IPTW was applied, Kaplan-Meier curves for OS and TTD were estimated, and a Cox model was used to estimate the HR of targeted therapy, IO monotherapy, and IO combination therapy vs chemotherapy.

As exploratory analyses, OS and TTD were estimated using Kaplan-Meier methods for the four 1L treatment categories and select baseline characteristics, including histology, ECOG PS, and tobacco use.

\section{Results}

\section{Study population}

In total, 7746 patients met eligibility criteria and were included in the analysis, with a median follow-up of 7.2 months (range, 0.0-47.1 months; Fig. 1; Table 2). Across the study population, the median age was 68 years (range, 26-90+ years), with $55.0 \%$ male and $66.2 \%$ having nonsquamous histology. Most patients (64.2\%) were diagnosed at stage IV. At initiation of 1L treatment, $64.1 \%$ had an ECOG PS of $0 / 1,18.9 \%$ had a PS of $2+$, and $17.0 \%$ lacked PS documentation. Most patients lacked documentation of biomarker mutational status.

\section{Treatment patterns}

The highest proportion of patients received $1 \mathrm{~L}$ systemic chemotherapy ( $n=5859$ [75.6\%]), followed by IO monotherapies $(n=907[11.7 \%)]$, targeted therapies $(n=656$ [8.5\%]), and IO combination regimens ( $n=324$ [4.2\%]; Table 2, Supplementary Table 1, Supplementary Figure 2). During the study observation period, 3620 patients $(46.7 \%)$ received 2L treatment (Supplementary Table 3). Of the 4126 patients who did not receive $2 \mathrm{~L}$ treatment, $1871(45.3 \%)$ died prior to $2 \mathrm{~L}$ treatment, $266(6.4 \%)$ had evidence of ongoing treatment, and 1989 (48.2\%) were lost to follow-up for unknown reasons. On the basis of the structured data available for this analysis, it was not possible to determine if the patients lost to follow-up transitioned to care outside the USON, were admitted to hospice, or died but did not have a record of death.

Higher proportions of patients who received IO therapies (22.4\% of IO monotherapy patients, $18.4 \%$ of IO combination therapy patients) had evidence of ongoing therapy at the end of the study observation period compared with those who received systemic chemotherapies $(1.2 \%)$ or targeted therapies (7.4\%; Supplementary Table 3). In total, $48.6 \%$, $43.6 \%, 37.0 \%$, and $34.8 \%$ of patients who received systemic chemotherapies, targeted therapies, IO monotherapies, and IO combination regimens, respectively, died before receiving $2 \mathrm{~L}$ treatment.

Figure 2 presents $1 \mathrm{~L}$ treatment category distribution over time. In the first complete quarter of the study period (second quarter of 2015), $2.1 \%$ of $1 \mathrm{~L}$ regimens included an IO therapy ( $1.7 \%$ monotherapy and $0.4 \%$ combination therapy). During the last complete quarter of the study period (the second quarter of 2018), 36.0\% of 1L regimens contained an IO therapy (22.9\% monotherapy and $13.1 \%$ combination therapy).

Across the $1 \mathrm{~L}$ treatment groups, $48.2 \%(n=2823)$ of patients who received systemic chemotherapies, $49.7 \%$ $(n=326)$ of patients who received targeted therapies, $78.4 \%$ $(n=710)$ of patients who received IO monotherapies, and $82.4 \%(n=267)$ of patients who received IO combination regimens did not receive $2 \mathrm{~L}$ treatment during the study observation period (Supplementary Figure 2). The most common treatment sequences were $1 \mathrm{~L}$ systemic chemotherapy to $2 \mathrm{~L}$ IO monotherapy $(n=2048)$ or $2 \mathrm{~L}$ systemic chemotherapy $(n=636)$. Among patients who received $1 \mathrm{~L}$ 
IO monotherapies, $15.7 \%(n=142)$ received $2 \mathrm{~L}$ systemic chemotherapy.

\section{Clinical outcomes}

Median TTD was 2.0 months (95\% CI, 1.9-2.1) with systemic chemotherapies vs 2.8 months (95\% CI, 2.4-3.1) with targeted therapies (unadjusted HR, $0.633 ; 95 \% \mathrm{CI}$, 0.583-0.688), 3.5 months (95\% CI, 2.8-4.2) with IO monotherapies (unadjusted HR, 0.405 ; 95\% CI, 0.374-0.438), and 3.0 months (95\% CI, 2.5-3.5) with IO combination regimens (unadjusted HR, 0.468; 95\% CI, 0.414-0.529; Fig. 3a).

Median OS was 14.9 months (95\% CI, 14.1-15.7) with systemic chemotherapies vs 18.5 months $(95 \%$ CI, 15.9-22.3) with targeted therapies (unadjusted HR, 0.830; 95\% CI, 0.733-0.941), 19.9 months (95\% CI, 16.6-24.1) with IO monotherapies (unadjusted HR, 0.908; 95\% CI, 0.810-1.019), and 14.0 months (95\% CI, 10.4-20.9) with IO combination regimens (unadjusted HR, 1.041; 95\% CI, $0.868-1.248$; Fig. 3b). The survival rate at 42 months was $25.9 \%$ (95\% CI, 23.9-27.9\%) across the study population and $24.8 \%$ (95\% CI, 22.7-27.0\%) with systemic chemotherapies, 31.1\% (95\% CI, 24.6-37.9\%) with targeted therapies, $31.0 \%$ (95\% CI, 21.4-41.0\%) with IO monotherapies, and $28.7 \%$ (95\% CI, 14.6-44.6\%) with IO combination therapies.

On the basis of multivariable Cox regression results, compared with patients who received 1L chemotherapy, lower risks of $1 \mathrm{~L}$ discontinuation occurred among those who received targeted therapies (HR, 0.633; 95\% CI, 0.581-0.689; $P<.0001$ ), IO monotherapy (HR, 0.390; 95\% CI, $0.360-0.423 ; P<.0001)$, or IO combination therapy (HR, 0.466; 95\% CI, 0.412-0.528; $P<.0001$; had lower risks of $1 \mathrm{~L}$ discontinuation Table 3). Receipt of $1 \mathrm{~L}$ targeted therapies and IO monotherapies was associated with a reduced risk of death compared with receipt of systemic chemotherapies (HR, 0.751; 95\% CI, 0.660-0.855; $P<$ .0001 and HR, 0.793; 95\% CI, 0.706-0.890; $P<.0001$, respectively; Table 3 ).

Additionally, several baseline covariates were statistically associated with increased risk of $1 \mathrm{~L}$ treatment discontinuation and/or increased risk of death (Table 4). Male sex, ECOG PS of 2+ or unknown (vs 0/1), documented metastases (lung, brain, bone, peritoneum, liver, or other), current or former tobacco use (vs never), and stage at diagnosis (stages IIA, IIB, IIIA, and no information vs IA) were associated with a significantly increased risk of treatment discontinuation. Obese BMI (vs normal), lung metastases, and squamous cell histology were associated with a significantly lower risk of discontinuation (all $P<.05$ ). Likewise, increased age, male sex, underweight BMI (vs normal), ECOG PS of 2+ or unknown (vs 0/1), documented metastases (brain, bone, liver, and other), and other histology (vs nonsquamous) were associated with a significantly increased risk of death, while obese and overweight BMI (vs normal) and lung metastases were associated with a significantly decreased risk of death (all $P<.05)$.

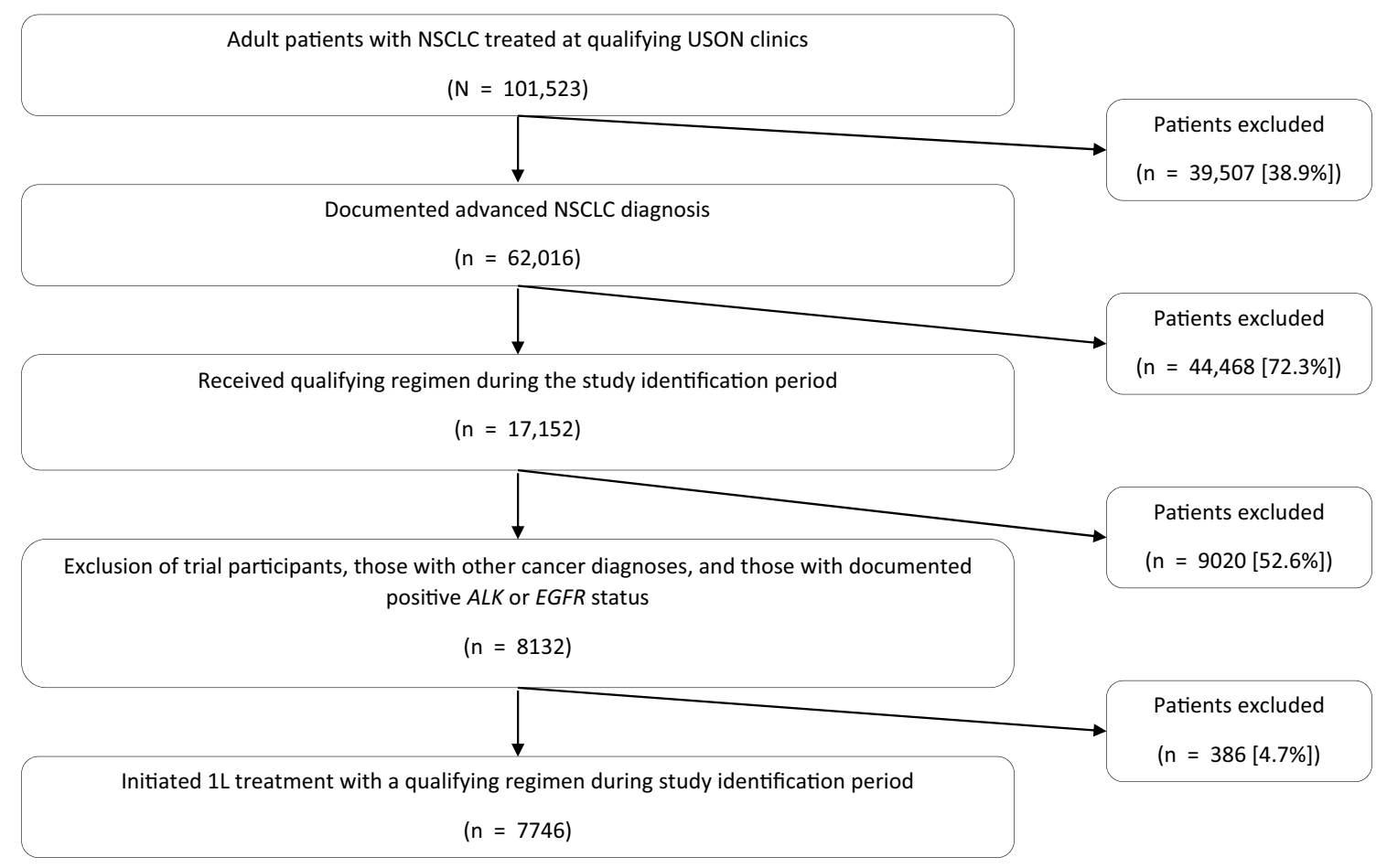

Fig. 1 Study attrition 
Table 2 Baseline demographic and clinical characteristics

\begin{tabular}{|c|c|c|c|c|c|}
\hline & $\begin{array}{l}\text { Overall } \\
(N=7746)\end{array}$ & $\begin{array}{l}\text { Systemic chemotherapies } \\
(n=5859)\end{array}$ & $\begin{array}{l}\text { Targeted therapies } \\
(n=656)\end{array}$ & $\begin{array}{l}\text { IO monotherapies } \\
(n=907)\end{array}$ & $\begin{array}{l}\text { IO combination regimens } \\
(n=324)\end{array}$ \\
\hline $\begin{array}{l}\text { Follow-up, median (range), } \\
\text { months }\end{array}$ & $7.2(0.0-47.1)$ & $7.3(0.0-47.1)$ & $7.6(0.0-47.1)$ & $6.7(0.0-46.1)$ & $5.9(0.0-42.4)$ \\
\hline $\begin{array}{l}\text { Time since initial NSCLC } \\
\text { diagnosis to index, median } \\
\text { (range), weeks }\end{array}$ & $6.1(0.0-1369.6)$ & $6.0(0.0-1369.6)$ & $5.3(0.0-907.6)$ & $8.1(0.0-860.3)$ & $6.4(0.3-856.3)$ \\
\hline $\begin{array}{l}\text { Time since advanced } \\
\text { NSCLC diagnosis to index, } \\
\text { median (range), weeks }\end{array}$ & $2.9(0.0-735.1)$ & $2.4(0.0-624.3)$ & $3.1(0.0-609.6)$ & $4.0(0.0-735.1)$ & $4.1(0.0-244.7)$ \\
\hline $\begin{array}{l}\text { Age at advanced NSCLC } \\
\text { diagnosis, median (range), } \\
\text { years }\end{array}$ & $68(26-90+)$ & $68(26-90+)$ & $66(29-89)$ & $70(27-90+)$ & $68(38-90+)$ \\
\hline Male sex, $n(\%)$ & $4261(55.0)$ & $3289(56.1)$ & 347 (52.9) & 468 (51.6) & $157(48.5)$ \\
\hline \multicolumn{6}{|l|}{ Race, $n(\%)$} \\
\hline Black/African American & 768 (9.9) & $599(10.2)$ & $62(9.5)$ & $83(9.2)$ & $24(7.4)$ \\
\hline White & $6109(78.9)$ & $4640(79.2)$ & $517(78.8)$ & $712(78.5)$ & $240(74.1)$ \\
\hline Other & $166(2.1)$ & $122(2.1)$ & $19(2.9)$ & $15(1.7)$ & $10(3.1)$ \\
\hline No information & $703(9.1)$ & $498(8.5)$ & $58(8.8)$ & $97(10.7)$ & $50(15.4)$ \\
\hline \multicolumn{6}{|l|}{ Tobacco use, $n(\%)$} \\
\hline Never & $801(10.3)$ & $536(9.1)$ & $123(18.8)$ & $95(10.5)$ & $47(14.5)$ \\
\hline Current & $3400(43.9)$ & $2643(45.1)$ & $262(39.9)$ & $379(41.8)$ & $116(35.8)$ \\
\hline Former & $3232(41.7)$ & 2439 (41.6) & $240(36.6)$ & $404(44.5)$ & $149(46.0)$ \\
\hline No information & $313(4.0)$ & $241(4.1)$ & $31(4.7)$ & $29(3.2)$ & $12(3.7)$ \\
\hline \multicolumn{6}{|l|}{ Body mass index, $n(\%)$} \\
\hline Underweight & $479(6.2)$ & $353(6.0)$ & $34(5.2)$ & $73(8.0)$ & $19(5.9)$ \\
\hline Normal & $3172(41.0)$ & $2371(40.5)$ & $272(41.5)$ & $390(43.0)$ & 139 (42.9) \\
\hline Overweight & $2349(30.3)$ & $1780(30.4)$ & $203(30.9)$ & $260(28.7)$ & $106(32.7)$ \\
\hline Obese & $1700(21.9)$ & $1341(22.9)$ & $133(20.3)$ & $166(18.3)$ & $60(18.5)$ \\
\hline Not documented & $46(0.6)$ & $14(0.2)$ & $14(2.1)$ & $18(2.0)$ & 0 \\
\hline \multicolumn{6}{|l|}{ Disease histology, $n(\%)$} \\
\hline Squamous cell carcinoma & $2114(27.3)$ & $1834(31.3)$ & $12(1.8)$ & $242(26.7)$ & $26(8.0)$ \\
\hline $\begin{array}{l}\text { Non-squamous cell carci- } \\
\text { noma }\end{array}$ & $5126(66.2)$ & $3629(61.9)$ & $588(89.6)$ & $629(69.4)$ & $280(86.4)$ \\
\hline Other & $230(3.0)$ & $188(3.2)$ & $20(3.0)$ & $16(1.8)$ & $6(1.9)$ \\
\hline No information & $276(3.6)$ & $208(3.6)$ & $36(5.5)$ & $20(2.2)$ & $12(3.7)$ \\
\hline \multicolumn{6}{|l|}{ Distant metastatic site(s), $n(\%)$} \\
\hline Brain & $890(11.5)$ & $647(11.0)$ & $65(9.9)$ & $124(13.7)$ & $54(16.7)$ \\
\hline Bone & $1472(19.0)$ & $1042(17.8)$ & $169(25.8)$ & $172(19.0)$ & $89(27.5)$ \\
\hline Liver & $616(8.0)$ & 445 (7.6) & $60(9.1)$ & $80(8.8)$ & $31(9.6)$ \\
\hline Lung & $1205(15.6)$ & $849(14.5)$ & $123(18.8)$ & $160(17.6)$ & $73(22.5)$ \\
\hline Peritoneum & $49(0.6)$ & $38(0.6)$ & $3(0.5)$ & $8(0.9)$ & 0 \\
\hline Other & $3406(44.0)$ & $2402(41.0)$ & $359(54.7)$ & $467(51.5)$ & $178(54.9)$ \\
\hline None/no information & $3178(41.0)$ & $2620(44.7)$ & $188(28.7)$ & $283(31.2)$ & $87(26.9)$ \\
\hline \multicolumn{6}{|l|}{ Stage at diagnosis, $n(\%)$} \\
\hline I-II & $799(10.3)$ & $614(10.5)$ & $44(6.7)$ & $122(13.5)$ & $19(5.9)$ \\
\hline III & $1652(21.3)$ & $1459(24.9)$ & $50(7.6)$ & $124(13.7)$ & $19(5.9)$ \\
\hline IV & $4974(64.2)$ & $3543(60.5)$ & $531(80.9)$ & $629(69.3)$ & $271(83.6)$ \\
\hline No information & $321(4.1)$ & $243(4.1)$ & $31(4.7)$ & $32(3.5)$ & $15(4.6)$ \\
\hline \multicolumn{6}{|l|}{ ECOG PS, $n(\%)$} \\
\hline $0 / 1$ & $4968(64.1)$ & $3774(64.4)$ & $420(64.0)$ & $565(62.3)$ & $209(64.5)$ \\
\hline $2+$ & $1462(18.9)$ & $1134(19.4)$ & $84(12.8)$ & $199(21.9)$ & 45 (13.9) \\
\hline
\end{tabular}


Table 2 (continued)

\begin{tabular}{|c|c|c|c|c|c|}
\hline & $\begin{array}{l}\text { Overall } \\
(N=7746)\end{array}$ & $\begin{array}{l}\text { Systemic chemotherapies } \\
(n=5859)\end{array}$ & $\begin{array}{l}\text { Targeted therapies } \\
(n=656)\end{array}$ & $\begin{array}{l}\text { IO monotherapies } \\
(n=907)\end{array}$ & $\begin{array}{l}\text { IO combination regimens } \\
(n=324)\end{array}$ \\
\hline No information & $1316(17.0)$ & $951(16.2)$ & $152(23.2)$ & $143(15.8)$ & $70(21.6)$ \\
\hline \multicolumn{6}{|l|}{ EGFR status, $n(\%)$} \\
\hline Negative & $1271(16.4)$ & $721(12.3)$ & $114(17.4)$ & $342(37.7)$ & $94(29.0)$ \\
\hline $\begin{array}{l}\text { Documented as unknown/ } \\
\text { no information }\end{array}$ & $6475(83.6)$ & $5138(87.7)$ & $542(82.6)$ & $565(62.3)$ & $230(71.0)$ \\
\hline \multicolumn{6}{|l|}{$A L K$ status, $n(\%)$} \\
\hline Negative & $1297(16.7)$ & $735(12.5)$ & $116(17.7)$ & 341 (37.6) & $105(32.4)$ \\
\hline $\begin{array}{l}\text { Documented as unknown/ } \\
\text { no information }\end{array}$ & $6449(83.3)$ & $5124(87.5)$ & $540(82.3)$ & $566(62.4)$ & $219(67.6)$ \\
\hline \multicolumn{6}{|l|}{ ROS1 status, $n(\%)$} \\
\hline Positive & $39(0.5)$ & $2(0.0)$ & $36(5.5)$ & $0(0.00)$ & $1(0.3)$ \\
\hline Negative & $1552(20.0)$ & $893(15.2)$ & $84(12.8)$ & $420(46.3)$ & $155(47.8)$ \\
\hline $\begin{array}{l}\text { Documented as unknown/ } \\
\text { no information }\end{array}$ & $6155(79.5)$ & $4964(84.7)$ & $536(81.8)$ & $487(53.7)$ & $168(51.8)$ \\
\hline \multicolumn{6}{|l|}{ PD-L1 status, $n(\%)$} \\
\hline Positive & $504(6.5)$ & $57(1.0)$ & $13(2.0)$ & $16(4.9)$ & $418(46.1)$ \\
\hline Negative & $425(5.5)$ & $307(5.2)$ & $21(3.2)$ & $68(21.0)$ & $29(3.2)$ \\
\hline $\begin{array}{l}\text { Documented as unknown/ } \\
\text { no information }\end{array}$ & $6817(88.0)$ & $5495(93.8)$ & $622(94.8)$ & $240(74.1)$ & $460(50.7)$ \\
\hline
\end{tabular}

$A L K$ anaplastic lymphoma kinase, ECOG PS Eastern Cooperative Oncology Group performance status, EGFR epidermal growth factor receptor, $I O$ immuno-oncology, NSCLC non-small cell lung cancer, $P D-L 1$ programmed death-ligand 1, ROS1 ROS proto-oncogene 1 receptor tyrosine kinase

Figure $4 \mathrm{a}$ and $\mathrm{b}$ present the weighted Kaplan-Meier curves for TTD and OS by treatment groups. IPTW-adjusted median TTD was 1.9 months (95\% CI, 1.7-2.0) with systemic chemotherapies vs 2.6 months $(95 \% \mathrm{CI}, 2.1-3.4)$ with targeted therapies (adjusted HR, 0.630; 95\% CI, 0.607-0.654), 4.2 months (95\% CI, 3.3-5.1) with IO monotherapies (adjusted HR, 0.410; 95\% CI, 0.386-0.416), and 3.5 months (95\% CI, 2.8-4.0) with IO combination regimens (adjusted HR, 0.426; 95\% CI, 0.410-0.442; Fig. 4a). For TTD, the treatment groups diverged prior to 6 months after 1L initiation with IO monotherapies or IO combination regimens, demonstrating reduced risk of discontinuation compared with systemic chemotherapies and targeted therapies (Fig. 4a). IO monotherapy was associated with the longest TTD until 12 months when its Kaplan-Meier curve began overlapping with that of IO combination therapy.

Weighted median OS was 14.5 months (95\% CI, 13.6-15.5) with systemic chemotherapies vs 23.0 months (95\% CI, 15.9-38.2) with targeted therapies (adjusted HR, 0.688; 95\% CI, 0.649-0.730), 25.6 months (95\% CI, 17.2-31.3) with IO monotherapies (adjusted HR, 0.727; 95\% CI, 0.688-0.768), and 16.0 months (95\% CI, 10.4-20.9) with IO combination regimens (adjusted HR, 0.937; 95\% CI, 0.889-0.988; Fig. 4b). OS across the groups was similar among targeted therapies and IO-based therapies for the first 10 months following $1 \mathrm{~L}$ initiation, then diverged with targeted therapies and IO monotherapies demonstrating superior survival rates compared with systemic chemotherapy and IO combination regimens. Interestingly, after about 10 months, IO combination therapy showed similar OS to chemotherapy.

Kaplan-Meier estimates of OS and TTD by age, histology, ECOG PS, and tobacco use for each treatment group are presented in Supplementary Table 4. Overall, IO monotherapy showed superior TTD and OS compared with other therapies consistently across different subgroups. However, the improved TTD or OS tended to be smaller in the following subgroups: age $\geq 65$ vs $<65$ years, squamous cell carcinoma vs non-squamous cell carcinoma, ECOG PS 2+ vs 0/1, and never used tobacco vs current or former tobacco use.

\section{Discussion}

To our knowledge, this is the latest study to investigate the real-world treatment patterns and clinical outcomes in patients with advanced NSCLC who initiated 1L treatment in a large network of community oncology practices. The demographic and clinical characteristics of this study population are similar to those reported in other real-world studies. A study by the Friends of Cancer Research (2018) compared patient characteristics and outcomes of patients with advanced NSCLC treated with IO therapies across 6 real-world databases (Friends of Cancer Research 2018). 


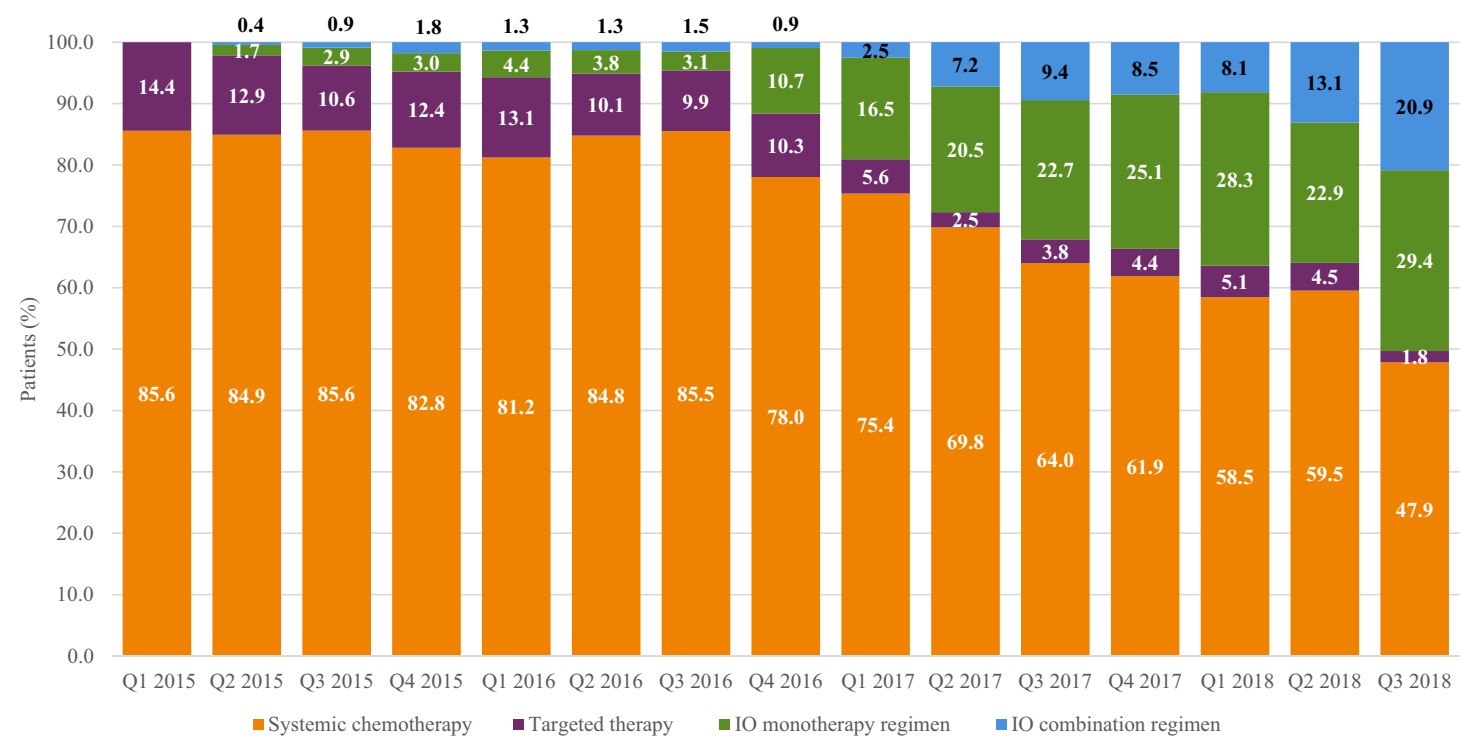

Fig. 2 First-line treatment distribution over time

The median age at advanced NSCLC diagnosis across these databases ranged from 64 to 70 years. More than half (range, $50-56 \%$ ) were male, with the majority being white (range, 65-87\%). Also similar to our study, the Friends of Cancer Research (2018) found that most patients had a history of smoking (range, 78-92\%), had been diagnosed with stage IV disease (range, 62-91\%), and had non-squamous cell carcinoma (range, 66-74\%). Khozin et al. (2018) observed similar characteristics in a multicenter analysis of data from The Flatiron Network: the median age was 69 years, 56\% were male, and $64 \%$ were diagnosed with stage IV disease.

Biomarker status, especially that of PD-L1 expression, was not documented within the structured fields of the iKM EHR for the majority of the study population. In total, 5.6\% of patients had a documented PD-L1-negative status, while $6.4 \%$ had a positive status. Khozin et al (2018) investigated IO use in patients with metastatic NSCLC and likewise observed that their PD-L1 status was rarely documented in the EHR. Among the 1344 patients included in their analysis, $8.0 \%$ had a record of PD-L1 testing. Future EHR-based studies should continue to monitor documentation of PD-L1 status because capture of this biomarker may increase over time as providers and payers adopt PD-L1 testing as standard practice for patients with NSCLC.

The treatment patterns observed in this study reflect the adoption of IO therapies in the US community oncology setting and are generally consistent with NCCN guideline recommendations. The first US Food and Drug Administration approval for $1 \mathrm{~L}$ treatment of NSCLC with an IO agent was granted in October 2016 for pembrolizumab monotherapy in patients whose tumor cell PD-L1 expression was $\geq$ $50 \%$ (Pai-Scherf et al. 2017). With the release of additional clinical trial data, the use of IOs in the $1 \mathrm{~L}$ setting has been expanded to include atezolizumab and pembrolizumab in combination with platinum-based chemotherapy regardless of the PD-L1 expression level (FDA approves atezolizumab with chemotherapy and bevacizumab for first-line treatment of metastatic non-squamous NSCLC (US Food and Drug Administration 2018a); FDA approves pembrolizumab in combination with chemotherapy for first-line treatment of metastatic squamous NSCLC (US Food and Drug Administration 2018b); FDA grants regular approval for pembrolizumab in combination with chemotherapy for first-line treatment of metastatic nonsquamous NSCLC (US Food and Drug Administration 2018c)).

Although previous real-world studies have shown high use of chemotherapy in the $1 \mathrm{~L}$ setting, these studies were based on data preceding the advent of IO treatments. (Khozin et al. 2019a; Simeone et al. 2019) For example, in a retrospective analysis of patients diagnosed with stage IV or metastatic NSCLC from January 2013 to January 2017, Simeone et al (2019) found that platinum-based regimens accounted for most of the 1L therapies (61.1\% of patients), while nivolumab comprised the most common $2 \mathrm{~L}$ and $3 \mathrm{~L}$ regimens ( $31.1 \%$ and $38.4 \%$ of patients, respectively). Similarly, in an analysis of patients treated with nivolumab or pembrolizumab from January 2011 through March 2016 for metastatic NSCLC in the Flatiron Health Network, the most common regimens preceding the earliest lines of IO treatment were platinum doublet-based therapies $(62.1 \%$ of patients) (Khozin et al. 2019a).

In this study, the proportion of patients receiving $1 \mathrm{~L} \mathrm{IO}$ therapy increased over the study period, from $2.1 \%$ in the second quarter of 2015 to $36.0 \%$ in the second quarter of 


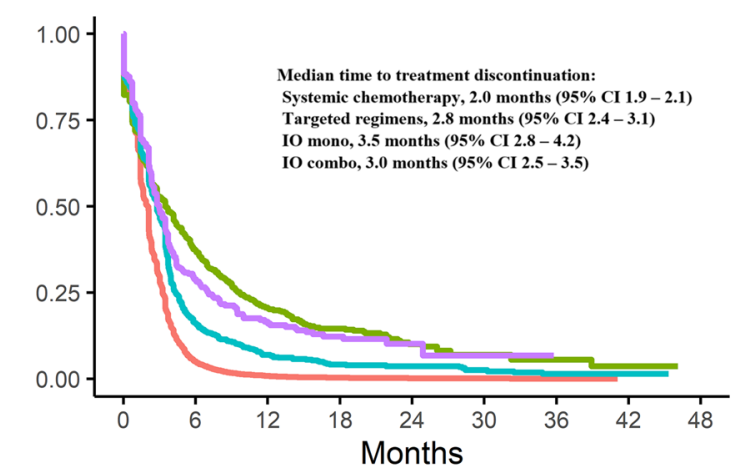

b
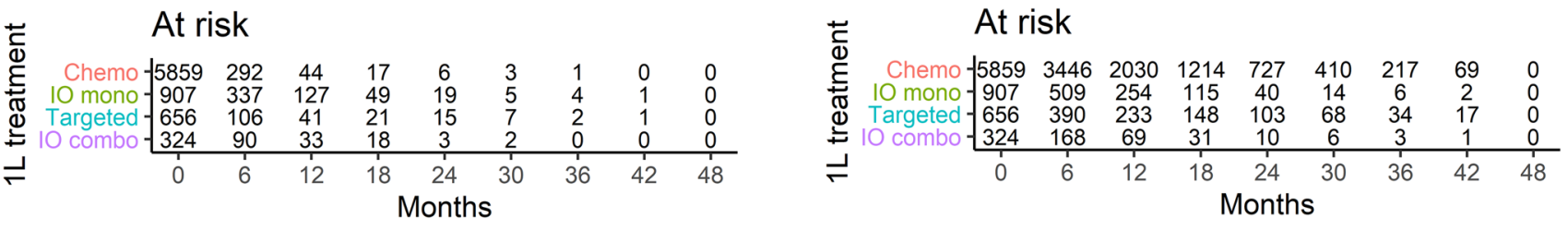

$1 \mathrm{~L}$ treatment $=$ Chemo $=10$ mono $=$ Targeted $=10$ combo

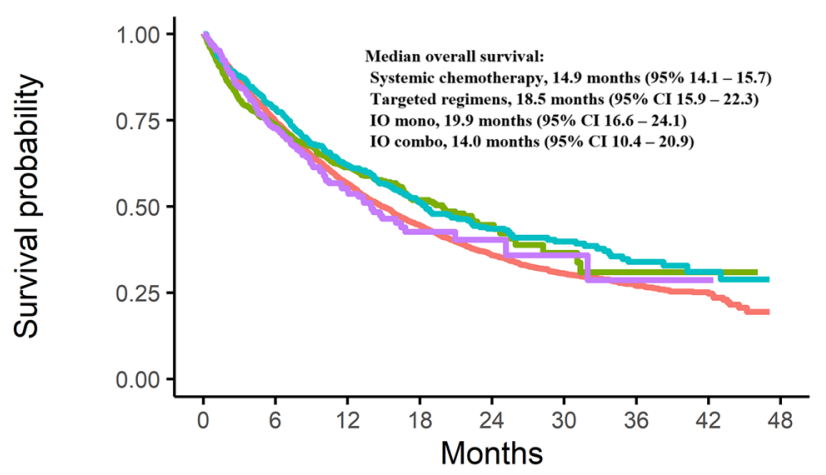

$1 \mathrm{~L}$ treatment $=$ Chemo -10 mono - Targeted $=10$ combo

Fig. 3 a Kaplan-Meier estimates of time to treatment discontinuation. b Kaplan-Meier estimates of overall survival

2018. However, high proportions of patients continued to receive $1 \mathrm{~L}$ systemic chemotherapies in 2018. Although IO combination therapies are being used more frequently, the initial approval for combination therapy was based on the KEYNOTE-189 trial results, which were released in the second quarter of 2018 (Gadgeel et al. 2020; Gandhi et al. 2018). Given the observation period of this study (1L initiation from March 1, 2015, to August 1, 2018), there was a limited period of time between the release of the clinical trial results and the study end date. Providers may have been cautious when adopting IO regimens into their practice; for example, they may have ordered IO therapies for their healthiest patients first because of the uncertainty about the clinical benefits and safety of these novel agents. Future research should consider whether there is increased adoption of IO therapies over a broader time period and, if not, what barriers might exist to more widespread use.

The apparently high attrition from $1 \mathrm{~L}$ to $2 \mathrm{~L}$ treatment in this study may reflect an unmet treatment need. Abernethy et al. 2017 reported a similar trend; of the patients who initiated $1 \mathrm{~L}$ treatment in their study, $42 \%$ received $2 \mathrm{~L}$ and $22 \%$ received $3 \mathrm{~L}$ treatment during the observation period. Although reasons for treatment discontinuation were not assessed as part of this analysis, previous studies have shown that common reasons include disease progression, toxicity, and worsening PS (Gajra et al. 2018; Sztankay et al. 2017; Walker et al. 2017). Therefore, treatments that provide a sustained response with a favorable safety profile may allow patients to continue $1 \mathrm{~L}$ treatment longer and eventually proceed to $2 \mathrm{~L}$ treatment rather than discontinuing treatment altogether.

Differences in the proportions of patients in each treatment group who received $2 \mathrm{~L}$ treatment were observed. Approximately $80 \%$ of patients who received IO regimens as $1 \mathrm{~L}$ did not have evidence of advancement to $2 \mathrm{~L}$, compared with $50 \%$ of those who received chemotherapies or targeted therapies. Ongoing treatment at the end of the study period was one reason for non-advancement, along with death or becoming lost to follow-up (Supplementary Table 3). A higher proportion of patients who received IO therapy had ongoing treatment compared to those who received chemotherapies or targeted therapies, which is likely due to the approval history of IO regimens. Likewise, the proportion of patients who died prior to $2 \mathrm{~L}$ treatment was lower in the IO treatment group than in the chemotherapy or targeted therapy groups.

The median TTD was significantly different across treatment groups (ranging from 2.0 months with systemic chemotherapies to 3.5 months with IO monotherapies; logrank $P$ value across all groups $<.0001)$. IO-based regimens were associated with longer TTD than chemotherapies and targeted therapies, which might be due to better tolerability of IO therapies. Blumenthal et al (2019) reviewed 18 randomized clinical trials conducted after 2007 in patients with metastatic NSCLC. They found a TTD of 3.5 months with immune checkpoint inhibitors compared with 3.8 months with chemotherapy doublet monotherapy and 2.2 months with chemotherapy monotherapies. Similarly, Stewart et al. 
Table 3 Treatment effect on time to treatment discontinuation and overall survival

\begin{tabular}{|c|c|c|c|c|c|c|}
\hline \multirow[t]{2}{*}{ Covariate } & \multirow[t]{2}{*}{ Level } & \multirow[t]{2}{*}{ Total } & \multirow{2}{*}{$\begin{array}{l}\text { Event (cen- } \\
\text { sored) }\end{array}$} & \multicolumn{3}{|c|}{ Hazard ratio (95\% confidence interval) } \\
\hline & & & & Unadjusted & Adjusted & IPTW adjusted \\
\hline \multirow[t]{4}{*}{$1 \mathrm{~L}$ treatment } & $\begin{array}{l}\text { Systemic chemotherapy } \\
\text { (reference) }\end{array}$ & 5859 & $5822(37)$ & - & - & - \\
\hline & Targeted therapies & 656 & $631(25)$ & $0.633(0.583-0.688)$ & $0.633(0.581-0.689)$ & $0.630(0.607-0.654)$ \\
\hline & IO monotherapy & 907 & $747(160)$ & $0.405(0.374-0.438)$ & $0.390(0.360-0.423)$ & $0.410(0.386-0.416)$ \\
\hline & IO combination therapy & 324 & $274(50)$ & $0.468(0.414-0.529)$ & $0.466(0.412-0.528)$ & $0.426(0.410-0.442)$ \\
\hline \multirow[t]{4}{*}{$1 \mathrm{~L}$ treatment } & $\begin{array}{l}\text { Systemic chemotherapy } \\
\text { (reference) }\end{array}$ & 5859 & $2796(3063)$ & - & - & - \\
\hline & Targeted therapies & 656 & $270(386)$ & $0.830(0.733-0.941)$ & $0.751(0.660-0.855)$ & $0.688(0.649-0.730)$ \\
\hline & IO monotherapy & 907 & $326(581)$ & $0.908(0.810-1.019)$ & $0.793(0.706-0.890)$ & $0.727(0.688-0.768)$ \\
\hline & IO combination therapy & 324 & $122(202)$ & $1.041(0.868-1.248)$ & $0.933(0.776-1.120)$ & $0.937(0.889-0.988)$ \\
\hline
\end{tabular}

(2019) used 6 real-world databases to assess clinical outcomes of patients with advanced NSCLC treated with IO regimens (in any line of therapy) and found that the median TTD ranged from 3.21 to 7.03 months.

The median TTD across treatment groups in this study appeared to be comparable to that of prior studies of chemotherapies, targeted therapies, and IO-based regimens. However, as a real-world proxy of PFS, the estimates were markedly shorter than PFS estimates in clinical trials (Table 1). Additionally, the TTD in this study may be shorter than treatment durations observed in clinical trials. For example, Velcheti et al. (2019) compared the real-world time on treatment (rwTOT) vs TOT in KEYNOTE-024 and -042 among patients with metastatic NSCLC and an ECOG PS of 0/1 treated with $1 \mathrm{~L}$ pembrolizumab. They reported a median rwTOT of 6.9 months vs a median TOT of 7.9 months in KEYNOTE-024 and 6.6 months in KEYNOTE-042. The median TTD of 3.5 months with IO monotherapy in our study was considerably shorter than the Velcheti et al (2019) estimates.

However, comparisons of these real-world results with clinical trials may reflect the underlying differences across patient populations and/or approaches to measurement. Specifically, more variation exists in the real-world settings with regard to patient and disease characteristics and clinical care practices, compared with the highly controlled care setting of clinical trials. For example, all patients had ECOG PS of 0/1 and stage IV disease in KEYNOTE-024, 042, and 407, as well as IMpower130 and 131, whereas our study population was not restricted to patients with favorable ECOG PS (Jotte et al. 2018, 2019; Mok et al. 2019a, b; Paz-Ares et al. 2018; Reck et al. 2016, 2019a, b; West et al. 2019). Also, PD-L1 status in this study was documented as unknown for nearly $90 \%$ of patients, while confirmation of PD-L1 status is frequently a selection criteria of IO clinical trials (Table 1).
The difference between the TTD in our study and the rwTOT in the Velcheti et al. (2019) study may reflect patient heterogeneity in our study. The median rwTOT among patients with ECOG PS of 2+ in the Velcheti et al. (2019) study was only 2.3 months, which is similar to the median TTD (2.1 months) observed for the same patient population in our study (Supplementary Table 4).

Few real-world studies have assessed OS in patients with advanced NSCLC who initiate 1L treatment in the era of IO therapies. Griffith et al. (2019) performed an EHR-based assessment of patients with advanced NSCLC who initiated 1L treatment between January 1, 2011, and February 28, 2018, and found a median OS of 10.98 months (95\% CI 10.79-11.18) across the patient population. Similarly, Stewart et al. (2019) reported that median OS ranged from 8.67 (95\% CI 6.83-10.02) to 15.78 months (95\% CI 12.20-24.59) among patients with advanced NSCLC who received IO therapies across 6 real-world databases.

The median OS results in this study appear to be similar, although shorter, to some estimates reported in key clinical trials (Table 1). In particular, median OS among patients who received IO monotherapies was 19.9 months in our study, which was comparable to that of KEYNOTE-042 and IMpower110 (both IO monotherapy), and the median OS of 14.0 months associated with IO combination therapies in our study was similar to that of KEYNOTE-407, IMpower131, IMpower150, and CheckMate 227 (all IO combination therapy) (Hellmann et al. 2018, 2019; Jotte et al. 2018, 2019; Mok et al. 2019a, b; Paz-Ares et al. 2018; Socinski et al. 2018a, b; Spigel et al. 2019). However, comparisons of results for IO combination therapies must be made with caution, as the results for KEYNOTE-407 and IMpower131 were specifically for squamous disease and the results for IMpower150 were specifically for non-squamous disease (Jotte et al. 2018, 2019; Paz-Ares et al. 2018; Socinski et al. 2018a, b). 
Table 4 Multivariable Cox regression analysis of time to treatment discontinuation and overall survival

\begin{tabular}{|c|c|c|c|c|c|}
\hline \multicolumn{6}{|c|}{ Time to treatment discontinuation } \\
\hline Covariate & Level & Total & $\begin{array}{l}\text { Event } \\
\text { (censored) }\end{array}$ & $\begin{array}{l}\text { Hazard ratio } \\
\text { ( } 95 \% \text { confidence interval) }\end{array}$ & $P$ value \\
\hline \multirow[t]{4}{*}{$1 \mathrm{~L}$ treatment } & Systemic chemotherapy (reference) & 5859 & $\begin{array}{l}5822 \\
(37)\end{array}$ & - & - \\
\hline & Targeted therapies & 656 & $\begin{array}{l}631 \\
(25)\end{array}$ & $\begin{array}{l}0.633 \\
(0.581-0.689)\end{array}$ & $<.0001$ \\
\hline & IO monotherapy & 907 & $\begin{array}{l}747 \\
(160)\end{array}$ & $\begin{array}{l}0.390 \\
(0.360-0.423)\end{array}$ & $<.0001$ \\
\hline & IO combination therapy & 324 & $\begin{array}{l}274 \\
(50)\end{array}$ & $\begin{array}{l}0.466 \\
(0.412-0.528)\end{array}$ & $<.0001$ \\
\hline \multirow[t]{2}{*}{ Sex } & Female (reference) & 3485 & $\begin{array}{l}3344 \\
(141)\end{array}$ & - & - \\
\hline & Male & 4261 & $\begin{array}{l}4130 \\
(131)\end{array}$ & $\begin{array}{l}1.053 \\
(1.005-1.103)\end{array}$ & .0302 \\
\hline \multirow[t]{5}{*}{ BMI } & Normal (reference) & 3172 & $\begin{array}{l}3064 \\
(108)\end{array}$ & - & - \\
\hline & No information & 63 & $\begin{array}{l}60 \\
(3)\end{array}$ & $\begin{array}{l}1.204 \\
(0.930-1.559)\end{array}$ & .1583 \\
\hline & Obese & 1686 & $\begin{array}{l}1630 \\
(56)\end{array}$ & $\begin{array}{l}0.904 \\
(0.851-0.961)\end{array}$ & .0012 \\
\hline & Overweight & 2343 & $\begin{array}{l}2250 \\
(93)\end{array}$ & $\begin{array}{l}0.953 \\
(0.902-1.007)\end{array}$ & .0847 \\
\hline & Underweight & 482 & $\begin{array}{l}470 \\
(12)\end{array}$ & $\begin{array}{l}1.037 \\
(0.940-1.143)\end{array}$ & .4730 \\
\hline \multirow[t]{3}{*}{ ECOG PS } & 0/1 (reference) & 4968 & $\begin{array}{l}4783 \\
(185)\end{array}$ & - & - \\
\hline & $2+$ & 1462 & $\begin{array}{l}1419 \\
(43)\end{array}$ & $\begin{array}{l}1.28 \\
(1.206-1.359)\end{array}$ & $<.0001$ \\
\hline & No information & 1316 & $\begin{array}{l}1272 \\
(44)\end{array}$ & $\begin{array}{l}1.097 \\
(1.027-1.171)\end{array}$ & .0057 \\
\hline \multirow[t]{2}{*}{ Lung metastases } & No (reference) & 6541 & $\begin{array}{l}6319 \\
(222)\end{array}$ & - & - \\
\hline & Yes & 1205 & $\begin{array}{l}1155 \\
(50)\end{array}$ & $\begin{array}{l}0.910 \\
(0.853-0.970)\end{array}$ & .0041 \\
\hline \multirow[t]{2}{*}{ Brain metastases } & No (reference) & 6856 & $\begin{array}{l}6620 \\
(236)\end{array}$ & - & - \\
\hline & Yes & 890 & $\begin{array}{l}854 \\
(36)\end{array}$ & $\begin{array}{l}1.092 \\
(1.014-1.175)\end{array}$ & .0203 \\
\hline \multirow[t]{2}{*}{ Bone metastases } & No (reference) & 6274 & $\begin{array}{l}6049 \\
(225)\end{array}$ & - & - \\
\hline & Yes & 1472 & $\begin{array}{l}1425 \\
(47)\end{array}$ & $\begin{array}{l}1.125 \\
(1.057-1.196)\end{array}$ & .0002 \\
\hline \multirow[t]{2}{*}{ Peritoneum metastases } & No (reference) & 7697 & $\begin{array}{l}7425 \\
(272)\end{array}$ & - & - \\
\hline & Yes & 49 & $\begin{array}{l}49 \\
(0)\end{array}$ & $\begin{array}{l}1.576 \\
(1.188-2.091)\end{array}$ & .0016 \\
\hline \multirow[t]{2}{*}{ Liver metastases } & No (reference) & 7130 & $\begin{array}{l}6875 \\
(255)\end{array}$ & - & - \\
\hline & Yes & 616 & $\begin{array}{l}599 \\
(17)\end{array}$ & $\begin{array}{l}1.107 \\
(1.016-1.208)\end{array}$ & .0209 \\
\hline \multirow[t]{2}{*}{ Other metastases } & No (reference) & 4340 & $\begin{array}{l}4201 \\
(139)\end{array}$ & - & -- \\
\hline & Yes & 3406 & $\begin{array}{l}3273 \\
(133)\end{array}$ & $\begin{array}{l}1.105 \\
(1.048-1.165)\end{array}$ & .0002 \\
\hline
\end{tabular}


Table 4 (continued)

Time to treatment discontinuation

\begin{tabular}{|c|c|c|c|c|c|}
\hline Covariate & Level & Total & $\begin{array}{l}\text { Event } \\
\text { (censored) }\end{array}$ & $\begin{array}{l}\text { Hazard ratio } \\
(95 \% \text { confidence interval })\end{array}$ & $P$ value \\
\hline \multirow[t]{9}{*}{ Stage at diagnosis } & IA (reference) & 164 & $\begin{array}{l}156 \\
(8)\end{array}$ & - & - \\
\hline & No information & 321 & $\begin{array}{l}315 \\
(6)\end{array}$ & $\begin{array}{l}1.237 \\
(1.005-1.522)\end{array}$ & .0446 \\
\hline & IB & 187 & $\begin{array}{l}180 \\
(7)\end{array}$ & $\begin{array}{l}1.191 \\
(0.961-1.477)\end{array}$ & .1111 \\
\hline & IIA & 235 & $\begin{array}{l}226 \\
(9)\end{array}$ & $\begin{array}{l}1.316 \\
(1.072-1.615)\end{array}$ & .0086 \\
\hline & IIB & 213 & $\begin{array}{l}209 \\
(4)\end{array}$ & $\begin{array}{l}1.273 \\
(1.034-1.568)\end{array}$ & .0231 \\
\hline & IIIA & 985 & $\begin{array}{l}969 \\
(16)\end{array}$ & $\begin{array}{l}1.229 \\
(1.036-1.458)\end{array}$ & .0177 \\
\hline & IIIB & 653 & $\begin{array}{l}644 \\
(9)\end{array}$ & $\begin{array}{l}1.183 \\
(0.992-1.411)\end{array}$ & .0616 \\
\hline & IIIC & 14 & $\begin{array}{l}13 \\
(1)\end{array}$ & $\begin{array}{l}1.105 \\
(0.627-1.947)\end{array}$ & .7305 \\
\hline & IV & 4974 & $\begin{array}{l}4762 \\
(212)\end{array}$ & $\begin{array}{l}1.133 \\
(0.965-1.331)\end{array}$ & .1271 \\
\hline \multirow[t]{5}{*}{ Tobacco use } & Never (reference) & 801 & $\begin{array}{l}750 \\
(51)\end{array}$ & - & - \\
\hline & Current & 3400 & $\begin{array}{l}3291 \\
(109)\end{array}$ & $\begin{array}{l}1.111 \\
(1.024-1.205)\end{array}$ & .0116 \\
\hline & Former & 3232 & $\begin{array}{l}3132 \\
(100)\end{array}$ & $\begin{array}{l}1.136 \\
(1.047-1.232)\end{array}$ & .0022 \\
\hline & Other & 151 & $\begin{array}{l}146 \\
(5)\end{array}$ & $\begin{array}{l}1.199 \\
(1.003-1.434)\end{array}$ & .0458 \\
\hline & No information & 162 & $\begin{array}{l}155 \\
(7)\end{array}$ & $\begin{array}{l}1.095 \\
(0.919-1.305)\end{array}$ & .3082 \\
\hline \multirow[t]{4}{*}{ Disease histology } & Non-squamous cell carcinoma (reference) & 5126 & $\begin{array}{l}4913 \\
(213)\end{array}$ & - & - \\
\hline & Other & 230 & $\begin{array}{l}223 \\
(7)\end{array}$ & $\begin{array}{l}1.069 \\
(0.934-1.224)\end{array}$ & .3328 \\
\hline & Squamous cell carcinoma & 2114 & $\begin{array}{l}2066 \\
(48)\end{array}$ & $\begin{array}{l}0.938 \\
(0.888-0.990)\end{array}$ & .0202 \\
\hline & No information & 276 & $\begin{array}{l}272 \\
(4)\end{array}$ & $\begin{array}{l}0.965 \\
(0.832-1.121)\end{array}$ & .6433 \\
\hline
\end{tabular}

Overall survival

\begin{tabular}{|c|c|c|c|c|c|}
\hline Covariate & Level & Total & $\begin{array}{l}\text { Event } \\
\text { (censored) }\end{array}$ & $\begin{array}{l}\text { Hazard ratio } \\
\text { (95\% confidence } \\
\quad \text { interval })\end{array}$ & Effect \\
\hline \multirow[t]{4}{*}{$1 \mathrm{~L}$ treatment } & $\begin{array}{l}\text { Systemic chemother- } \\
\text { apy (reference) }\end{array}$ & 5859 & $\begin{array}{l}2796 \\
(3063)\end{array}$ & - & - \\
\hline & Targeted therapies & 656 & $\begin{array}{l}270 \\
(386)\end{array}$ & $\begin{array}{l}0.751 \\
(0.660-0.855)\end{array}$ & $<.0001$ \\
\hline & IO monotherapy & 907 & $\begin{array}{l}326 \\
(581)\end{array}$ & $\begin{array}{l}0.793 \\
(0.706-0.890)\end{array}$ & $<.0001$ \\
\hline & $\begin{array}{l}\text { IO combination } \\
\text { therapy }\end{array}$ & 324 & $\begin{array}{l}122 \\
(202)\end{array}$ & $\begin{array}{l}0.933 \\
(0.776-1.120)\end{array}$ & .4560 \\
\hline
\end{tabular}


Table 4 (continued)

\begin{tabular}{|c|c|c|c|c|c|}
\hline \multicolumn{6}{|l|}{ Overall survival } \\
\hline $\begin{array}{l}\text { Age at advanced } \\
\text { NSCLC diagnosis, } \\
\text { years }\end{array}$ & Per year increase & 7746 & $\begin{array}{l}3514 \\
(4232)\end{array}$ & $\begin{array}{l}1.007 \\
(1.003-1.011)\end{array}$ & .0001 \\
\hline \multirow[t]{2}{*}{ Sex } & Female (reference) & 3485 & $\begin{array}{l}1499 \\
(1986)\end{array}$ & - & - \\
\hline & Male & 4261 & $\begin{array}{l}2015 \\
(2246)\end{array}$ & $\begin{array}{l}1.183 \\
(1.106-1.267)\end{array}$ & $<.0001$ \\
\hline \multirow[t]{5}{*}{ BMI } & Normal (reference) & 3172 & $\begin{array}{l}1492 \\
(1680)\end{array}$ & - & - \\
\hline & No information & 63 & $\begin{array}{l}20 \\
(43)\end{array}$ & $\begin{array}{l}0.992 \\
(0.637-1.545)\end{array}$ & .9713 \\
\hline & Obese & 1686 & $\begin{array}{l}708 \\
(978)\end{array}$ & $\begin{array}{l}0.808 \\
(0.738-0.884)\end{array}$ & $<.0001$ \\
\hline & Overweight & 2343 & $\begin{array}{l}1060 \\
(1283)\end{array}$ & $\begin{array}{l}0.895 \\
(0.827-0.969)\end{array}$ & .0059 \\
\hline & Underweight & 482 & $\begin{array}{l}234 \\
(248)\end{array}$ & $\begin{array}{l}1.246 \\
(1.084-1.431)\end{array}$ & .0019 \\
\hline \multirow[t]{3}{*}{ ECOG PS } & 0/1 (reference) & 4968 & $\begin{array}{l}2202 \\
(2766)\end{array}$ & - & - \\
\hline & $2+$ & 1462 & $\begin{array}{l}790 \\
(672)\end{array}$ & $\begin{array}{l}1.689 \\
(1.556-1.835)\end{array}$ & $<.0001$ \\
\hline & No information & 1316 & $\begin{array}{l}522 \\
(794)\end{array}$ & $\begin{array}{l}1.182 \\
(1.070-1.305)\end{array}$ & .0010 \\
\hline \multirow[t]{2}{*}{ Lung metastases } & No (reference) & 6541 & $\begin{array}{l}2965 \\
(3576)\end{array}$ & - & - \\
\hline & Yes & 1205 & $\begin{array}{l}549 \\
(656)\end{array}$ & $\begin{array}{l}0.873 \\
(0.795-0.958)\end{array}$ & .0044 \\
\hline \multirow[t]{2}{*}{ Brain metastases } & No (reference) & 6856 & $\begin{array}{l}3052 \\
(3804)\end{array}$ & - & - \\
\hline & Yes & 890 & $\begin{array}{l}462 \\
(428)\end{array}$ & $\begin{array}{l}1.171 \\
(1.056-1.298)\end{array}$ & .0027 \\
\hline \multirow[t]{2}{*}{ Bone metastases } & No (reference) & 6274 & $\begin{array}{l}2698 \\
(3576)\end{array}$ & - & - \\
\hline & Yes & 1472 & $\begin{array}{l}816 \\
(656)\end{array}$ & $\begin{array}{l}1.421 \\
(1.306-1.546)\end{array}$ & $<.0001$ \\
\hline \multirow[t]{2}{*}{ Liver metastases } & No (reference) & 7130 & $\begin{array}{l}3171 \\
(3959)\end{array}$ & - & - \\
\hline & Yes & 616 & $\begin{array}{l}343 \\
(273)\end{array}$ & $\begin{array}{l}1.265 \\
(1.126-1.421)\end{array}$ & $<.0001$ \\
\hline \multirow[t]{2}{*}{ Other metastases } & No (reference) & 4340 & $\begin{array}{l}1818 \\
(2522)\end{array}$ & - & - \\
\hline & Yes & 3406 & $\begin{array}{l}1696 \\
(1710)\end{array}$ & $\begin{array}{l}1.259 \\
(1.165-1.360)\end{array}$ & $<.0001$ \\
\hline
\end{tabular}


Table 4 (continued)

\begin{tabular}{|c|c|c|c|c|c|}
\hline \multicolumn{6}{|l|}{ Overall survival } \\
\hline \multirow[t]{9}{*}{ Stage at diagnosis } & IA (reference) & 164 & $\begin{array}{l}66 \\
(98)\end{array}$ & - & - \\
\hline & No information & 321 & $\begin{array}{l}87 \\
(234)\end{array}$ & $\begin{array}{l}0.941 \\
(0.668-1.326)\end{array}$ & .7284 \\
\hline & IB & 187 & $\begin{array}{l}73 \\
(114)\end{array}$ & $\begin{array}{l}0.928 \\
(0.665-1.296)\end{array}$ & .6624 \\
\hline & IIA & 235 & $\begin{array}{l}94 \\
(141)\end{array}$ & $\begin{array}{l}0.880 \\
(0.642-1.207)\end{array}$ & .4281 \\
\hline & IIB & 213 & $\begin{array}{l}86 \\
(127)\end{array}$ & $\begin{array}{l}0.934 \\
(0.677-1.289)\end{array}$ & .6783 \\
\hline & IIIA & 985 & $\begin{array}{l}414 \\
(571)\end{array}$ & $\begin{array}{l}0.855 \\
(0.658-1.111)\end{array}$ & .2411 \\
\hline & IIIB & 653 & $\begin{array}{l}280 \\
(373)\end{array}$ & $\begin{array}{l}0.895 \\
(0.683-1.172)\end{array}$ & .4191 \\
\hline & IIIC & 14 & $\begin{array}{l}1 \\
(13)\end{array}$ & $\begin{array}{l}0.262 \\
(0.036-1.891)\end{array}$ & .1843 \\
\hline & IV & 4974 & $\begin{array}{l}2413 \\
(2561)\end{array}$ & $\begin{array}{l}1.209 \\
(0.945-1.546)\end{array}$ & .1321 \\
\hline \multirow[t]{4}{*}{ Disease histology } & $\begin{array}{l}\text { Non-squamous cell } \\
\text { carcinoma (refer- } \\
\text { ence) }\end{array}$ & 5126 & $\begin{array}{l}2347 \\
(2779)\end{array}$ & - & - \\
\hline & Other & 230 & $\begin{array}{l}113 \\
(117)\end{array}$ & $\begin{array}{l}1.361 \\
(1.126-1.646)\end{array}$ & .0015 \\
\hline & $\begin{array}{l}\text { Squamous cell carci- } \\
\text { noma }\end{array}$ & 2114 & $\begin{array}{l}980 \\
(1134)\end{array}$ & $\begin{array}{l}1.001 \\
(0.925-1.082)\end{array}$ & .9869 \\
\hline & No information & 276 & $\begin{array}{l}74 \\
(202)\end{array}$ & $\begin{array}{l}0.943 \\
(0.722-1.231)\end{array}$ & .6652 \\
\hline
\end{tabular}

$1 L$ first-line, $B M I$ body mass index, ECOG PS Eastern Cooperative Oncology Group performance status, $I O$ immuno-oncology

Differences in clinical outcomes by histology were observed in this study, with IO monotherapies having less impact on survival among patients with squamous cell carcinoma vs those with non-squamous cell carcinoma (Supplementary Table 4). KEYNOTE-407 reported that patients who received IO combination therapy (chemotherapy plus paclitaxel) exhibited a longer median OS than patients who received chemotherapy alone (HR, 0.64; 95\% CI $0.49-0.85 ; P<.001)$, but mixed results were reported in IMpower131 (Jotte et al. 2018, 2019 Paz-Ares et al. 2018). IMpower131 contained 3 treatment arms: patients in arms $\mathrm{A}$ and $\mathrm{B}$ received atezolizumab and carboplatin with either paclitaxel or $n a b$-paclitaxel, respectively, while those in arm $\mathrm{C}$ received carboplatin and $n a b$-paclitaxel (Jotte et al. 2018, 2019) Patients in arm B demonstrated an improved PFS compared with those in arm C (HR, 0.715; 95\% CI, 0.603-0.848; $P=.0001)$, but this benefit was not observed in patients in arm A and was not replicated for OS.

Several factors were associated with a decreased risk of treatment discontinuation and death, including overweight
BMI (vs normal). While the correlation between BMI and these treatment outcomes is unclear, it is possible that patients who experience minimal weight loss have less aggressive forms of disease or diminished levels of circulating cytokines associated with cachexia (An et al. 2020; Kichenadasse et al. 2019).

The results of the multivariable Cox regression analysis suggest a clinical benefit of IO therapies; in particular, IO monotherapy was significantly associated with a reduced risk of $1 \mathrm{~L}$ treatment discontinuation and death (both $P<$ .0001). This trend was also illustrated in the Kaplan-Meier curves adjusted by the IPTW method, which demonstrated that patients who received IO monotherapies had improved TTD and OS compared with those of systemic chemotherapies. However, the improved clinical outcomes associated with the IO monotherapies, especially OS, were most pronounced in specific patient subgroups (ie, patients with non-squamous cell carcinoma and those with ECOG PS of 0/1). Additional studies are needed to confirm the clinical benefit of IO monotherapy in other patient subgroups, such 

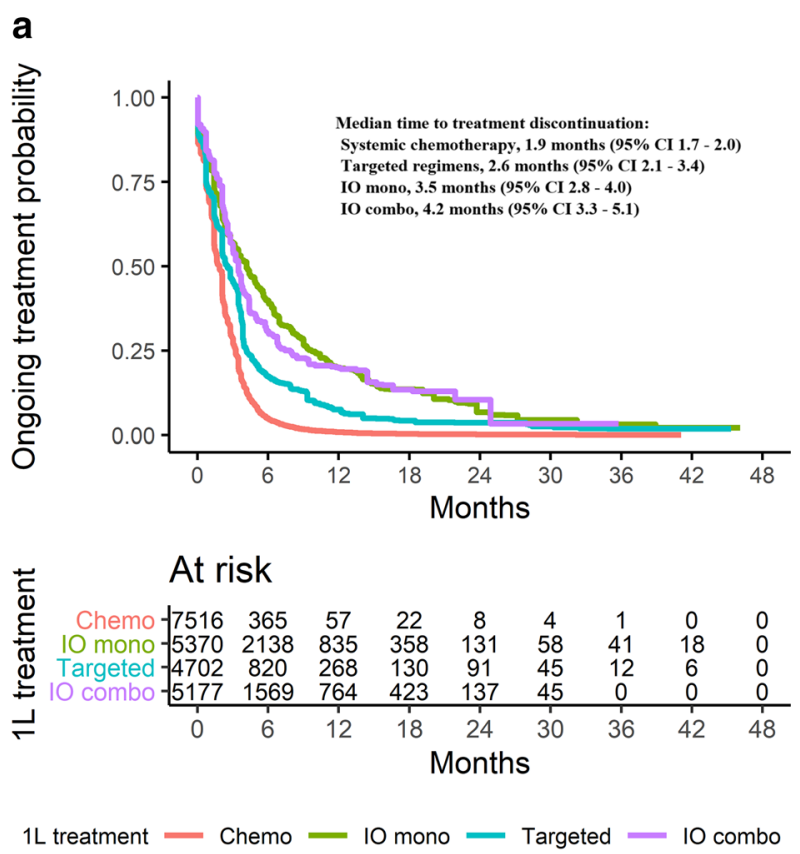

b
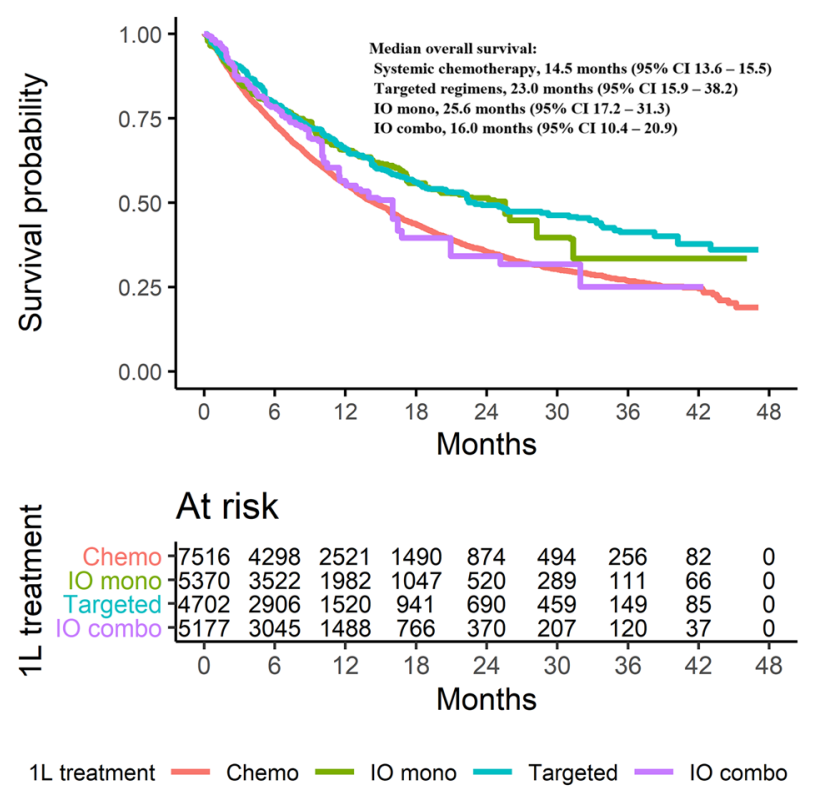

Fig. 4 a Inverse probability weighting estimates of time to treatment discontinuation. b Inverse probability weighting estimates of overall survival

as patients with squamous cell carcinoma, older patients (aged $\geq 65$ years), and those with former tobacco use (Supplementary Table 4).

While we did not specifically compare IO monotherapy to IO combination therapy, our results suggest that IO monotherapy was associated with more favorable survival rates than IO combination therapy, which exhibited survival trends similar to those of systemic chemotherapy, even after adjusting with IPTW. In KEYNOTE-024, median OS was 26.3 months (95\% CI 18.3-40.4) among patients who received pembrolizumab monotherapy, compared to 22.0 months $(95 \%$ CI 19.5, 25.2) among patients who received pembrolizumab combination therapy in KEYNOTE-189 trial, (Table 1); (Gadgeel et al. 2020; Reck et al. 2016, 2019a, b). Because IO combination therapies are being more frequently used after recent approval, future studies should determine if uncontrolled patient- or treatment-related factors, such as PD-L1 status, toxicity, management of toxicity, as well as sample size, may have influenced these outcomes.

This study is subject to several limitations. First, the low capture of PD-L1 information limited the assessment of outcomes by PD-L1 status, and the results may have been confounded by inclusion of $E G F R$ - or $A L K$-positive patients who had a missing/unknown status in their EHR. An exploratory analysis was performed to assess exclusion of the small proportion of patients who received targeted therapies indicated for $1 \mathrm{~L}$ treatment of patients with EGFR mutations or $A L K$ rearrangements ( $n=116[1.5 \%$ of the study population]). The results of this analysis did not yield meaningful differences in the baseline characteristics, TTD, or OS of the study population (data not shown); thus, these patients were retained for the final analyses, as their biomarker status could not be confirmed.

Additionally, because this was a retrospective observational study, patients were not assigned to treatment groups, and underlying clinical differences may have influenced outcomes. The sample size was also unbalanced across the treatment groups, with a substantially higher proportion of patients receiving $1 \mathrm{~L}$ systemic chemotherapy than the other $1 \mathrm{~L}$ treatments. To reduce bias due to patient heterogeneity, adjusted analyses were performed to control for selected covariates, although unobserved factors (eg, PD-L1 status) may have confounded the results.

Approximately $50 \%$ of patients did not receive $2 \mathrm{~L}$ treatment for unknown reasons. These patients may have received $2 \mathrm{~L}$ treatment outside the USON, or their death date was not captured; as a result, TTD and OS for these patients may be misrepresented. While the proportions of patients who did not receive $2 \mathrm{~L}$ treatment for unknown reasons were similar, it is unclear how patients without follow-up information may have influenced the study results.

Finally, differences in USON treatment practices or the patient population may have influenced the results. Specifically, the USON encourages the use of evidence-based treatment that reflects a refinement of the $\mathrm{NCCN}$ guidelines (Hoverman et al. 2014; National Comprehensive Cancer Network McKesson 2019). Although USON clinics are located across the US, a high proportion of clinics are 
located in southern regions. As such, USON patients may be different than other community oncology patient populations or patients treated in academic settings. Thus, the results of this study are most generalizable to community-based oncology clinics that also adhere to best-practice guidelines consistent with NCCN guidelines.

By sourcing data from a large network of communitybased oncology clinics, this study provides insights into patient profiles, treatment patterns, and outcomes in a large population of patients with advanced NSCLC. These results supplement findings from clinical trials, as patients who were not enrolled in clinical trials were included in the analysis. Therefore, treatment trends and clinical outcomes reflect how current therapeutic options are being used in the community oncology setting.

\section{Conclusions}

These results provide insight into current treatment use and outcomes associated with 1L treatment of advanced NSCLC in a real-world setting. Although the treatment landscape appears to be shifting in response to expanded approvals for IO therapies, a high proportion of patients still receive systemic chemotherapy, and many do not appear to advance to $2 \mathrm{~L}$ treatment. Our results indicate that targeted therapies and IO monotherapies were associated with the most favorable clinical outcomes; the longest median TTD and OS occurred with IO monotherapies. However, the clinical benefit of IO monotherapies may be limited in certain patient subgroups, including those with squamous cell carcinoma and ECOG PS of 2+. Unlike IO monotherapy, IO combination therapy appeared to be associated with similar survival trends as systemic chemotherapy. This finding may have been influenced by underlying differences between the treatment subgroups that could not statistically be controlled (eg, PD-L1 expression).

The results of this study suggest that patients treated in this real-world setting exhibited similar, but shorter, median OS and markedly lower median TTD compared with PFS in clinical trials. The lower TTD observed in this study may be due to differences in measurement, effectiveness, and/or tolerability of treatment in a heterogeneous population of patients treated in the community oncology setting. Overall, these findings suggest the continued need to develop safe and effective treatments for advanced NSCLC. As these therapeutic advancements are released, future studies should continue to use available real-world data to monitor outcomes associated with $1 \mathrm{~L}$ regimen choice.

Acknowledgements This study was sponsored by Pfizer as part of an alliance between Merck KGaA, Darmstadt, Germany and Pfizer. The authors thank Lisa Kaspin-Powell (McKesson Life Sciences) for copyediting, editorial, and production assistance with the preparation of this manuscript.

Author contributions Dr. Nadler, Dr. Arondekar, Ms. Chang, Dr. Zhang and Dr. Pawar report that they contributed to the design of the study, interpretation of results and critical review of the manuscript. Ms. Aguilar reports that she contributed to the design of the study, interpretation of the results and drafting of the manuscript. Dr. Zhou reports that she contributed to the acquisition of the data, analysis of the data and critical review of the manuscript. All authors read and approved the final manuscript.

Funding This study was sponsored by Pfizer as part of an alliance between Merck KGaA, Darmstadt, Germany and Pfizer. Employees of Pfizer and EMD Serono Research \& Development Institute, Inc., a business of Merck KGaA, Darmstadt, Germany, were involved in the study design, analysis and interpretation of the data and writing of the report.

Availability of data and material (data transparency) The health data used to support the findings of this study are restricted by the US Oncology Institutional Review Board in order to protect patient privacy. For this reason, data used to support the findings of this study have not been made available.

Code availability (software application or custom code) Statistical coding used to conduct the analyses is proprietary and, as such, has not been made available.

\section{Compliance with ethical standards}

Conflict of Interest Dr. Nadler reports that he was employed by Texas Oncology and provided research support to Pfizer and Merck KGaA, Darmstadt, Germany, during the course of the study. Dr. Arondekar and Ms. Chang report that they were employed by Pfizer during the course of the study. Ms. Aguilar and Dr. Zhou report that they were employed by McKesson Life Sciences and provided research support to Pfizer and Merck KGaA, Darmstadt, Germany during the course of the study. Dr. Zhang and Dr. Pawar report that they were employed by EMD Serono Research \& Development Institute, Inc., a business of Merck KGaA, Darmstadt, Germany, during the course of the study.

Ethics approval and consent to participate The study was reviewed and granted an exception and waiver of consent by the US Oncology, Inc, Institutional Review Board. This study was conducted in accordance with the Declaration of Helsinki.

Consent for publication All authors have reviewed the final version of the manuscript and are in agreement its content and submission.

Open Access This article is licensed under a Creative Commons Attribution 4.0 International License, which permits use, sharing, adaptation, distribution and reproduction in any medium or format, as long as you give appropriate credit to the original author(s) and the source, provide a link to the Creative Commons licence, and indicate if changes were made. The images or other third party material in this article are included in the article's Creative Commons licence, unless indicated otherwise in a credit line to the material. If material is not included in the article's Creative Commons licence and your intended use is not permitted by statutory regulation or exceeds the permitted use, you will need to obtain permission directly from the copyright holder. To view a copy of this licence, visit http://creativecommons.org/licenses/by/4.0/. 


\section{References}

Abernethy AP, Arunachalam A, Burke T, McKay C, Cao X, Sorg R, Carbone DP (2017) Real-world first-line treatment and overall survival in non-small cell lung cancer without known EGFR mutations or ALK rearrangements in US community oncology setting. PLoS One 12:e0178420. https://doi.org/10.1371/journ al.pone. 0178420

An Y, Wu Z, Wang N, Yang Z, Li Y, Xu B, Sun M (2020) Association between body mass index and survival outcomes for cancer patients treated with immune checkpoint inhibitors: a systematic review and meta-analysis. J Transl Med 18:235. https://doi. org/10.1186/s12967-020-02404-x

Azim HA, Ganti AK, Elattar I, Azim H, Loberiza FR (2016) Triplets vs. doublets in the management of advanced non-small cell lung cancer (NSCLC) using third generation chemotherapeutic agents: A meta-analysis. J Clin Oncol 25:7580

Azim HA Jr, Elattar I, Loberiza FR Jr, Azim H, Mok T, Ganti AK (2009) Third generation triplet cytotoxic chemotherapy in advanced non-small cell lung cancer: a systematic overview. Lung Cancer 64:194-198. https://doi.org/10.1016/j.lungc an.2008.08.011

Bittoni MA et al (2018) Real-world treatment patterns, overall survival, and occurrence and costs of adverse events associated with first-line therapies for medicare patients 65 years and older with advanced non-small-cell lung cancer: a retrospective study. Clin Lung Cancer 19:e629-e645. https://doi.org/10.1016/j. cllc.2018.04.017

Blumenthal GM et al (2019) Analysis of time-to-treatment discontinuation of targeted therapy, immunotherapy, and chemotherapy in clinical trials of patients with non-small-cell lung cancer. Ann Oncol 30:830-838. https://doi.org/10.1093/annonc/mdz060

Bursac Z, Gauss CH, Williams DK, Hosmer DW (2008) Purposeful selection of variables in logistic regression Source Code. Biol Med 3:17. https://doi.org/10.1186/1751-0473-3-17

European Medicines Agency (2017) Guideline on the evaluation of anticancer medicinal products in man. https://www.ema.europ a.eu/en/documents/scientific-guideline/guideline-evaluation-antic ancer-medicinal-products-man-revision-5_en.pdf. Accessed Jan 14,2020

Friends of Cancer Research. Establishing a Framework to Evaluate Real-World Endpoints. (2018). https://www.focr.org/sites/default/ files/pdf/RWE_FINAL\%25207.6.18.pdf. Accessed Dec 16, 2019

Gadgeel S et al (2020) Updated analysis from KEYNOTE-189: pembrolizumab or placebo plus pemetrexed and platinum for previously untreated metastatic nonsquamous non-small-cell lung cancer. J Clin Oncol 38:1505-1517. https://doi.org/10.1200/ JCO.19.03136

Gajra A et al (2018) Time-to-treatment-failure and related outcomes among 1000+ advanced non-small cell lung cancer patients: comparisons between older versus younger patients (Alliance A151711). J Thorac Oncol 13:996-1003. https://doi. org/10.1016/j.jtho.2018.03.020

Gandhi L et al (2018) Pembrolizumab plus chemotherapy in metastatic non-small-cell lung cancer. N Engl J Med 378:2078-2092. https ://doi.org/10.1056/NEJMoa1801005

Griffith SD et al (2019) Characterizing the feasibility and performance of real-world tumor progression end points and their association with overall survival in a large advanced non-small-cell lung cancer data set JCO Clin Cancer Inform 3:1-13. https://doi. org/10.1200/CCI.19.00013

Harder VS, Stuart EA, Anthony JC (2010) Propensity score techniques and the assessment of measured covariate balance to test causal associations in psychological research. Psychol Methods 15:234 249. https://doi.org/10.1037/a0019623
Hellmann MD et al (2018) Nivolumab plus ipilimumab in lung cancer with a high tumor mutational burden. N Engl J Med 378:20932104. https://doi.org/10.1056/NEJMoa1801946

Hellmann MD et al (2019) Nivolumab plus ipilimumab in advanced non-small-cell lung cancer. N Engl J Med 381:2020-2031. https ://doi.org/10.1056/NEJMoa1910231

Hoverman JR et al (2014) Opening the black box: the impact of an oncology management program consisting of level I pathways and an outbound nurse call system. J Oncol Pract 10:63-67. https ://doi.org/10.1200/JOP.2013.001210

Jotte RM et al (2019) IMpower 131: Final overall survival results of IMpower131 trial in advanced squamous NSCLC. In: World Conference on Lung Cancer, Barcelona, Spain, Sep 7-10 2019

Jotte RM et al (2018) IMpower131: Primary PFS and safety analysis of a randomized phase III study of atezolizumab + carboplatin + paclitaxel or nab-paclitaxel vs carboplatin + nab-paclitaxel as $1 \mathrm{~L}$ therapy in advanced squamous NSCLC. J Clin Oncol 36:LBA9000

Kang JDY, Schafer JL (2007) Demystifying double robustness: a comparison of alternative strategies for estimating a population mean from incomplete data. Stat Sci 22:523-539

Kaniski F, Enewold L, Thomas A, Malik S, Stevens JL, Harlan LC (2017) Temporal patterns of care and outcomes of non-small cell lung cancer patients in the United States diagnosed in 1996, 2005, and 2010. Lung Cancer 103:66-74. https://doi.org/10.1016/j.lungc an.2016.11.020

Khozin S et al (2018) Characteristics of real-world metastatic nonsmall cell lung cancer patients treated with nivolumab and pembrolizumab during the year following approval. Oncologist 23:328-336. https://doi.org/10.1634/theoncologist.2017-0353

Khozin S et al (2019a) Real-world outcomes of patients with metastatic non-small cell lung cancer treated with programmed cell death protein 1 inhibitors in the year following U.S Regulatory Approval. Oncologist 24:648-656. https://doi.org/10.1634/theon cologist.2018-0307

Khozin S et al (2019b) Real-world progression, treatment, and survival outcomes during rapid adoption of immunotherapy for advanced non-small cell lung cancer. Cancer. https://doi.org/10.1002/ cncr.32383

Kichenadasse G, Miners JO, Mangoni AA, Rowland A, Hopkins AM, Sorich MJ (2019) Association between body mass index and overall survival with immune checkpoint inhibitor therapy for advanced non-small cell lung cancer. JAMA Oncol. https://doi. org/10.1001/jamaoncol.2019.5241

Lee BK, Lessler J, Stuart EA (2010) Improving propensity score weighting using machine learning. Stat Med 29:337-346. https ://doi.org/10.1002/sim.3782

McCaffrey DF, Griffin BA, Almirall D, Slaughter ME, Ramchand R, Burgette LF (2013) A tutorial on propensity score estimation for multiple treatments using generalized boosted models. Stat Med 32:3388-3414. https://doi.org/10.1002/sim.5753

McKesson. Value Pathways powered by NCCN-Oncology Clinical Pathways. (2019). https://www.mckesson.com/specialty/oncol ogy-pathways/. Accessed 11/27/19

Mok TSK et al (2019a) Final analysis of the phase III KEYNOTE-042 study: Pembrolizumab (Pembro) versus platinum-based chemotherapy (Chemo) as first-line therapy for patients (Pts) with PD-L1-positive locally advanced/metastatic NSCLC (Abstract 1020). Ann Oncol. https://doi.org/10.1093/annonc/mdz063

Mok TSK et al (2019b) Pembrolizumab versus chemotherapy for previously untreated, PD-L1-expressing, locally advanced or metastatic non-small-cell lung cancer (KEYNOTE-042): a randomised, open-label, controlled, phase 3 trial. Lancet 393:1819-1830. https ://doi.org/10.1016/S0140-6736(18)32409-7

Molife C, Hess LM, Cui ZL, Li XI, Beyrer J, Mahoui M, Oton AB (2019) Sequential therapy with ramucirumab and/or checkpoint 
inhibitors for non-small-cell lung cancer in routine practice. Future Oncol (London, England) 15:2915-2931. https://doi. org/10.2217/fon-2018-0876

Nadler E, Espirito JL, Pavilack M, Boyd M, Vergara-Silva A, Fernandes A (2018) Treatment patterns and clinical outcomes among metastatic non-small-cell lung cancer patients treated in the community practice setting. Clin Lung Cancer 19:360-370. https://doi. org/10.1016/j.cllc.2018.02.002

National Comprehensive Cancer Network NCCN, McKesson Specialty Health, and The US Oncology Network Announce Plans for Integration with Elekta and Varian

NCCN Guidelines for Non-Small Cell Lung Cancer 6.2020 Clinical practice guidelines in oncology: non-small cell lung cancer version 6.2020 .

Pai-Scherf L et al (2017) FDA approval summary: pembrolizumab for treatment of metastatic non-small cell lung cancer: First-Line Therapy and Beyond. Oncologist 22:1392-1399. https://doi. org/10.1634/theoncologist.2017-0078

Papadimitrakopoulou V et al (2018) IMpower132: PFS and safety results with $1 \mathrm{~L}$ atezolizumab + carboplatin/cisplatin + pemetrexed in stage IV non-squamous NSCLC (OA0507). J Thoracic Oncol 13:S332-S333. https://doi.org/10.1016/j.jtho.2018.08.262

Paz-Ares L et al (2018) Pembrolizumab plus chemotherapy for squamous non-small-cell lung cancer. N Engl J Med 379:2040-2051. https://doi.org/10.1056/NEJMoa1810865

RAND Corporation (2020) Toolkit for weighting and analysis of nonequivalent groups (TWANG). https://www.rand.org/statistics/ twang.html. Accessed Jan 16, 2020

Reck M et al. KEYNOTE-024 3-year survival update: pembrolizumab vs platinum-based chemotherapy for advanced non-small-cell lung cancer In: World Conference on Lung Cancer, Barcelona, Spain Sep 7-10 2019a.

Reck M et al (2016) Pembrolizumab versus Chemotherapy for PDL1-positive non-small-cell lung cancer. N Engl J Med 375:18231833. https://doi.org/10.1056/NEJMoa1606774

Reck M et al (2019) Updated analysis of KEYNOTE-024: pembrolizumab versus platinum-based chemotherapy for advanced nonsmall-cell lung cancer with PD-L1 tumor proportion score of 50\% or greater. J Clin Oncol 37:537-546. https://doi.org/10.1200/ JCO.18.00149

Schwartzberg L, Korytowsky B, Penrod JR, Zhang Y, Le TK, Batenchuk C, Krug L (2019) Real-world clinical impact of immune checkpoint inhibitors in patients with advanced/metastatic non-small cell lung cancer after platinum chemotherapy. Clin Lung Cancer 20:287-296.e284. https://doi.org/10.1016/j. cllc.2019.04.004

Simeone JC, Nordstrom BL, Patel K, Klein AB (2019) Treatment patterns and overall survival in metastatic non-small-cell lung cancer in a real-world US setting. Future Oncol (London, England) 15:3491-3502. https://doi.org/10.2217/fon-2019-0348

Socinski MA, Jotte RM, Cappuzzo F, Orlandi F, Stroyakovskiy D, Nogami N (2018a) Overall survival (OS) analysis of IMpower150, a randomized $\mathrm{Ph} 3$ study of atezolizumab (atezo) + chemotherapy (chemo) \pm bevacizumab (bev) vs chemo + bev in $1 \mathrm{~L}$ nonsquamous (NSQ) NSCLC. J Clin Oncol 36

Socinski MA et al (2018) Atezolizumab for first-line treatment of metastatic nonsquamous NSCLC. N Engl J Med 378:2288-2301. https ://doi.org/10.1056/NEJMoa1716948

Spigel D et al (2019) Interim overall survival (OS) analysis of a phase III study of atezolizumab (atezo) vs platinum-based chemotherapy (chemo) as first-line (1L) treatment (tx) in PD-L1-selected
NSCLC. In: ESMO, Barcelona, Spain. Annals of Oncology, pp v851-v934

Stewart M et al (2019) An exploratory analysis of real-world end points for assessing outcomes among immunotherapy-treated patients with advanced non-small-cell lung cancer. JCO Clin Cancer Inform 3:1-15. https://doi.org/10.1200/CCI.18.00155

Sztankay M et al. (2017) Clinical decision-making and health-related quality of life during first-line and maintenance therapy in patients with advanced non-small cell lung cancer (NSCLC): findings from a real-world setting BMC Cancer 17:565 https://doi.org/10.1186/ s12885-017-3543-7

The US Oncology Network. (2018). https://www.usoncology.com/ourcompany. Accessed 21 Jan 2019

Velcheti V, Chandwani S, Chen X, Pietanza MC, Burke T (2019) Firstline pembrolizumab monotherapy for metastatic PD-L1-positive NSCLC: real-world analysis of time on treatment. Immunotherapy 11:889-901. https://doi.org/10.2217/imt-2019-0061

Walker MS, Wong W, Ravelo A, Miller PJE, Schwartzberg LS (2017) Effectiveness outcomes and health related quality of life impact of disease progression in patients with advanced nonsquamous NSCLC treated in real-world community oncology settings: results from a prospective medical record registry study. Health Qual Life Outcomes 15:160. https://doi.org/10.1186/s1295 5-017-0735-4

Weis TM, Hough S, Reddy HG, Daignault-Newton S, Kalemkerian GP (2019) Real-world comparison of immune checkpoint inhibitors in non-small cell lung cancer following platinum-based chemotherapy. J Oncol Pharm Prac. https://doi.org/10.1177/1078155219 855127

West $\mathrm{H}$ et al (2019) Atezolizumab in combination with carboplatin plus nab-paclitaxel chemotherapy compared with chemotherapy alone as first-line treatment for metastatic non-squamous nonsmall-cell lung cancer (IMpower130): a multicentre, randomised, open-label, phase 3 trial. Lancet Oncol 20:924-937

US Food and Drug Administration (2018a) www.FDA.gov. FDA approves atezolizumab with chemotherapy and bevacizumab for first-line treatment of metastatic non-squamous NSCLC. . https ://www.fda.gov/drugs/fda-approves-atezolizumab-chemotherapyand-bevacizumab-first-line-treatment-metastatic-non-squamous. Accessed Dec 10, 2019

US Food and Drug Administration (2018b) www.FDA.gov. FDA approves pembrolizumab in combination with chemotherapy for first-line treatment of metastatic squamous NSCLC. https://www. fda.gov/drugs/fda-approves-pembrolizumab-combination-chemo therapy-first-line-treatment-metastatic-squamous-nsclc. Accessed Dec 10, 2019

US Food and Drug Administration (2018c) www.FDA.gov. FDA grants regular approval for pembrolizumab in combination with chemotherapy for first-line treatment of metastatic nonsquamous NSCLC. . https://www.fda.gov/drugs/resources-infor mation-approved-drugs/fda-grants-regular-approval-pembrolizu mab-combination-chemotherapy-first-line-treatment-metastatic. Accessed Decr 10, 2019

Xia W et al (2017) Improvement of survival for non-small cell lung cancer over time. Onco Targets Ther 10:4295-4303. https://doi. org/10.2147/ott.s145036

Publisher's Note Springer Nature remains neutral with regard to jurisdictional claims in published maps and institutional affiliations. 